\title{
1. DER WEG NACH BERLIN
}

\subsection{Schicksal Deutschland}

"Ja«, bekannte André François-Poncet im Sommer 1932 gegenüber Harry Graf Kessler, "es sei wie eine Art Fatum, das ihn immer wieder seit seinem vierzehnten Lebensjahr nach Deutschland zurückführe «" Tatsächlich hatte der spätere Botschafter 1901/1902 ein halbes Jahr die Unterprima des Großherzoglichen Gymnasiums zu Offenburg besucht ${ }^{2}$. Dieser erste Deutschlandaufenthalt hatte bei André François-Poncet einen tiefen Eindruck hinterlassen, der sich allerdings, wie zu zeigen sein wird, erst Jahre später manifestieren sollte. Schon im Herbst 1903 unternahm er eine zweite Reise nach Deutschland, die ihn von Heidelberg über Frankfurt und Mainz den Rhein hinab bis nach Bonn führte. Die überlieferten Reisenotizen des 16jährigen beschränken sich indes auf ästhetische Betrachtungen, ohne $d a B$ auch nur eine Bemerkung zu den von der deutsch-französischen Geschichte gezeichneten Sehenswürdigkeiten am Rhein zu finden wäre: Kein Wort zur Zerstörung des Heidelberger Schlosses 1689 und auch kein Kommentar zur historisch-politischen Bedeutung des Niederwalddenkmals ${ }^{3}$. Offensichtlich war sich der 16jährige angesichts der historischen Orte der deutsch-französischen Vergangenheit noch nicht bewußt. Die »schicksalhafte« Orientierung André François-Poncets auf Deutschland geht auf seinen Vater zurück. Henri François-Poncet ließ seinen

1 KESSLER, Tagebücher, S. 716. Die zuverlässigste und ergiebigste Quelle zum Leben André François-Poncets ist die Laudatio Pierre Benoits zu dessen Aufnahme in die Académie française, Discours de réception de M. André François-Poncet à l'Académie française et réponse de M. Pierre Benoit, Paris 1953. Vgl. auch die Laudatio Edgar Faures auf André François-Poncet, dem er in die Akademie folgte: Discours de réception de $\mathrm{M}$. Edgar Faure à l'Académie française et réponse de M. le duc de Castries, Paris 1979.

2 Vgl. Großherzogliches Gymnasium zu Offenburg, Jahresbericht über das Schuljahr 19011902, S. 7ff., in: AN/AP 462, 1. Nach eigenen Angaben war André François-Poncet in diesem Jahr auch in Stuttgart, um seine Sprach- und Geschichtskenntnisse zu verbessern, vgl. André FRANÇOIS-PONCET, Zu Deutschen gesprochen, München 1958, S. 7f. Der Aufenthalt ist im Nachlaß nicht belegt. Infolgedessen nennt Bock zuletzt nur den Aufenthalt an dem Gymnasium in Offenburg, vgl. DERS., Rapports, S. 129. Daß François-Poncet "zeitweilig die Schule in Stuttgart und Dresden « besucht haben soll, behauptet Bock nur in Perzeption, S. 587. Diese Behauptung beruht wohl auf einem Mißverständnis Benoits, der die Grundlage für François-Poncets Studie »Ce que pense la jeunesse allemande « in derem Studium in Stuttgart, Dresden, München und Berlin sah, vgl. BeNolt, Réponse, S. 110 bzw. André FranÇols-PONCET, Ce que pense la jeunesse allemande, Paris 1913, S. 37.

3 Vgl. André FRANÇOIS-PONCET, Notes de Voyage en Allemagne, in: AN/AP 462, 1. 
am 13. Juni 1887 in Provins, gut 100 Kilometer westlich von Paris, geborenen Sohn Deutsch lemen ${ }^{4}$. Keine ungewöhnliche Entscheidung zu der Zeit schließlich galt Deutschland in den 90er Jahren des 19. Jahrhunderts als die aufstrebende Macht. Das Beispiel mag den Einfluß andeuten, den der Vater auf den ersten Sohn der Familie ausuibte ${ }^{5}$. André François-Poncet wurde geprägt von den politischen Vorstellungen des Familienoberhauptes, das von seiner Herkunft, seinen Erfahrungen und seinem Beruf geprägt war ${ }^{6}$. Als Jurist im Staatsdienst kann er als gemäßigter Republikaner gelten, der sich am Sieger von Sedan orientierte ${ }^{7}$. Diese Orientierung war typisch in der III. Republik, die aus der vernichtenden Niederlage des Zweiten Kaiserreiches gegen Deutschland hervorgegangen war. Die III. Republik konnte im letzten Drittel des 19. Jahrhunderts nicht nur ihren Bestand sichern, sondern auch das zweitgrößte Kolonialreich der Welt aufbauen und ein stetiges Wirtschaftswachstum verzeichnen. Zugleich erreichte der französische Impressionismus in Malerei, Literatur und Musik seinen Höhepunkt. Sicher, die innere und äußere Entwicklung der III. Republik verlief nicht ohne Probleme, der Panama-Skandal, die Dreyfus-Affäre und die Faschoda-Krise seien als Stichworte genannt, dennoch herrschte bei den Franzosen um die Jahrhundertwende eine positive Grundstimmung vor, die zumindest das Lebensgefühl André François-Poncets in den ersten Jahren günstig beeinflußt haben dürfte ${ }^{8}$.

Kindheit und Jugend verbrachte André François-Poncet an den Dienstorten seines Vaters, der als Magistrat von Provins zunächst nach Tonnerre, dann nach Meaux und 1896 schließlich als Conseiller an den Cour d'appel nach Paris versetzt wurde ${ }^{9}$. Er besuchte in Paris die Eliteschulen der Hauptstadt:

4 André François-Poncet soll eine »deutsche Gouvernante« gehabt haben, vgl. »Ein Zeuge tritt ab«, in: Der Spiegel vom 2. März 1955, S. 11. Diese Behauptung findet sich nirgends bestätigt. Ab der $9^{e}$ belegte André François-Poncet im collège als erste Fremdsprache Deutsch, siehe AN/AP 462, 1.

5 Zum Einfluß des Vaters siehe FAURE, Discours, S. 17, BENOIT, Réponse, S. 109, BocK, Perzeption, S. 587 sowie das Selbstzeugnis in: SOLO, Ambassador, S. 2f.: »I lived in his shadow... All my youth was marked by the influence of this man and those ideas which were then considered subversive by the bourgeoisie«. (Taped interview with André François-Poncet, June 23, 1973.)

6 Siehe zu den Lebensverhältnissen und politischen Vorstellungen der französischen Bourgeoisie Jean-Baptiste DUROSELLE, La France de la >Belle Époque`, Paris ${ }^{2} 1992$.

7 Vgl. dazu Klaus HEITMANN, Das französische Deutschlandbild in seiner historischen Entwicklung (I), in: Sociologia Internationalis 4 (1966) S. 73-101, hier S. 100f.

8 Historiker ordnen als Biographen geme das Geburtsjahr ihres Protagonisten in den geschichtlichen Zusammenhang ein, um den späteren Lebensweg zu begründen. Dieser historisch-deterministische Ansatz bringt die frühe Kindheit in einen universal- bzw. nationalgeschichtlichen Zusammenhang, der nicht besteht. Eltern, Familie und spăter die Schule spielen in der Primärsozialisation die entscheidende Rolle. Infolgedessen wurde an dieser Stelle bewuBt auf eine detailliertere Darstellung des national- bzw. Universalgeschichtlichen Hintergrundes verzichtet.

9 Zu den Stationen siehe FAURE, Discours, S. 17 und BENOIT, Réponse, S. 107. 
Lycée Carnot, Collège Stanislas und Lycée Henri IV. Seine Schulleistungen waren gut, obwohl er immer einer der jüngsten in seiner Klasse war ${ }^{10}$. 1903/1904 legte er das Baccalauréat mit der "mention assez bien « ab und bereitete sich anschließend auf den Concours général vor, den er 1906 als Fünfter (Lettres) bestand. An der École Normale Supérieure studierte André François-Poncet danach Germanistik ${ }^{11}$. Unter dem Einfluß seiner akademischen Lehrer Charles Andler ${ }^{12}$, Henri Lichtenberger ${ }^{13}$ und Fernand Baldensperger $^{14}$ las er die Werke der deutschen Romantik und Klassik und schrieb über Goethes Wahlverwandtschaften eine nach wie vor bemerkenswerte Abschlußarbeit ${ }^{15}$, die er während eines Studienaufenthaltes in Deutschland 1907/1908 vorbereitet hatte. André François-Poncet hatte in diesem Wintersemester an der Königlichen Friedrich-Wilhelms-Universität zu Berlin und im Sommersemester an der Königlich Bayerischen Ludwig-Maximilians-Universität München Vorlesungen über Goethe, Schiller und Lessing gehört. Das Studienjahr im wilhelminischen Deutschland hinterließ - wie schon der vorhergehende Schulaufenthalt - einen tiefen Eindruck, der zwar erst einige Jahre später zum Ausdruck kommen sollte, der aber das Deutschlandbild André

10 Vgl. die im NachlaB vollständig vorliegenden Schulzeugnisse, AN/AP 462, 1.

11 Laut BENOIT, Réponse, S. 109 und FAURE, Discours, S. 18 trat François-Poncet 1907 in die ENS ein. Das ist falsch. André François-Poncet wurde im Sommer 1906 aufgenommen, vgl. das Certificat d'admission à l'École Normale Supérieure vom 19. Juli 1906, in: AN/AP 462, 1. Bock folgte den fehlerhaften Darstellungen in DERS., Skizze, S. 382, wiederholte sie aber weder in DERS., Perzeption, S. 587 noch in DERS., Rapports, S. 129. Messemer datiert den Studienbeginn an der ENS richtig auf das Jahr 1906, vgl. MESSEMER, François-Poncet, S. 506f.

12 Charles Andler (1866-1933), Literaturhistoriker an der ENS (seit 1893), an der Sorbonne (seit 1901) und am Collège de France (seit 1926) arbeitete über Nietzsche, Bismarck und den »Pangermanismus«. $\mathrm{Zu}$ seinem Einfluß auf die französische Germanistik siehe Elisabeth DECULTOT, La section d'allemand de l'École Normale Supérieure depuis la fin du XIX $X^{e}$ siècle jusqu'à la veille de la seconde guerre mondiale, in: Michel ESPAGNE (Hg.), L'École Normale Supérieure et l'Allemagne, Leipzig 1995, S. 39-66.

13 Henri Lichtenberger (1864-1941), Germanist an der Sorbonne, schrieb über Nietzsche, Wagner und »L'Allemagne moderne«. Zu Leben und Werk siehe Hans Manfred BOCK, Henri Lichtenberger, père fondateur de la germanistique française et médiateur entre la France et l'Allemagne, in: Michel ESPAGNE, Michael WERNER (Hg.), Histoire des études germaniques en France (1900-1970), Paris 1994, S. 155-169.

14 Fernand Baldensperger (1871-1958), Literaturhistoriker an der Sorbonne, arbeitete u. a. über Goethe in Frankreich. Zur Einschätzung seiner akademischen Lehrer vgl. André FRANÇOIS-PONCET, Meine Beziehungen zu Goethe. Ansprache seiner Excellenz des Herrn Botschafters André François-Poncet Hohen Kommissars der Französischen Republik in Deutschland anläßlich der Goethefeier am 28. August 1949 in der Aula der Johannes-Gutenberg-Universität, die gemeinsam von der Stadt Mainz und der Universität veranstaltet wurde, Mainz 1949, S. 12 .

${ }^{15}$ André FrançoIs-PONCET, Les affinités électives de Goethe. Préface de Henri Lichtenberger, Paris 1910. Die Studie erschien auch auf deutsch: DERS., Goethes Wahlverwandtschaften. Versuch eines kritischen Kommentars, Mainz 1951. 
François-Poncets bis ins hohe Alter prägte. Zunächst schloß der Germanistikstudent 1910 sein Studium mit Bravour ab. Obwohl ihm als Jahrgangsbestem die Tür zur akademischen Welt weit offen stand, entschied sich der 23jährige, als Gymnasiallehrer nach Montpellier zu gehen ${ }^{16}$. Der Deutschunterricht scheint den Germanisten jedoch nicht ausgefüllt zu haben, so daß er sich noch im Schuljahr 1910/1911 für ein Stipendium an der Fondation Thiers bewarb. Als Pensionär angenommen, kehrte André François-Poncet im Herbst 1911 nach Paris zurück und widmete sich literaturwissenschaftlichen und ideengeschichtlichen Studien ${ }^{17}$.

Gleichzeitig wurde er publizistisch tätig: Er arbeitete für »L'Opinion«, für die »Revue politique internationale« und andere Zeitschriften. In »L'Opinion« veröffentlichte André François-Poncet im Mai 1913 eine Artikelserie über die Jugend im wilhelminischen Deutschland, mit der der Germanist erstmals öffentlich Aufmerksamkeit erregte ${ }^{18}$. Unter dem Titel "Ce que pense la jeunesse allemande « erschienen die Artikel noch im gleichen Jahr als Buch ${ }^{19}$. Anlaß für die Veröffentlichung war die Diskussion in Frankreich, ob auf die deutsche Gesetzesvorlage von 1913 zur Aufstockung des Heeres um 200000 Mann mit einer Verlängerung der französischen Dienstpflicht (auf drei Jahre) reagiert werden solle. Grundlage und Kern der Veröffentlichung ist ein Vortrag, den André François-Poncet bereits am 16. März 1911 gehalten hatte ${ }^{20}$. Angesichts der sich verschärfenden Spannungen zwischen Deutschland und Frankreich wegen Marokko ${ }^{21}$ aktualisierte der 24jährige seine bisherigen Deutschland-Erfahrungen und stellte sie unter dem Titel "L'esprit militaire des Allemands« einer uns heute unbekannten Zuhörerschaft vor. Nach André François-Poncets Darstellung entstand der militärische Geist bei den Deutschen erst infolge der preußischen Reformen von Stein, Hardenberg und York, war also keine spontane Entwicklung, sondern »il fut semé dans une terre neuve et cultivée rationnellement, méthodiquement et patiemment «. Insofern sei der deutsche Militärgesit ursprünglich »une plantation artificielle $\ll^{22}$. Ganz in der Tradition des romantischen Deutschlandbildes der Franzosen sprach André François-Poncet dem deutschen Volk einen »natürlichen« Militärgeist

Siehe dazu DERS., Discours français, Paris 1930, S. 62-64 und das Romanfragment "La vie montpellierainne et régionale« im Nachlaß, AN/AP 462, 1.

17 Vgl. die Notizen für einen Tätigkeitsbericht für die Fondation Thiers, AN/AP 462, 1.

18 L'Opinion vom 3. Mai 1913, S. 545ff., vom 10. Mai 1913, S. 577ff., vom 17. Mai 1913, S. 627ff. und vom 24. Mai 1913, S. 611f. Zur Resonanz auf die Publikation siehe Gilbert ZIEBURA, Die deutsche Frage in der öffentlichen Meinung Frankreichs von 1911 bis 1914, Berlin 1955, S. 184.

19 FranÇOIS-PONCET, Jeunesse.

20 Das Redemanuskript findet sich im Nachlaß, AN/AP 462, 4.

21 Zur 2. Marokko-Krise siehe Gregor SCHOLlGEN, Das Zeitalter des Imperialismus, München ${ }^{4} 2000$, S. 80.

22 André FRANÇOIS-PONCET, L'esprit militaire des Allemands, S. 2r. 
ab: "L'Allemand, dans le fond, n'est pas batailleur; il est bonace; c'est l'homme par excellence des joies familiales et des amitiés démonstratives; il ne demande qu'à travailler, à acquérir du bien-être pour lui et les siens « ${ }^{23}$. Trotz der friedliebenden Züge konnte der militärische Geist im deutschen Volk Wurzeln schlagen, weil den Deutschen ein zweiter Charakterzug zu eigen sei: »une capacité vaniteuse, une puissance d'orgueil prodigieuse ${ }^{24}$. Mit militärischen Erfolgen konnte der latente Hochmut der Deutschen geweckt und in einen militärischen Stolz umgewandelt werden. Die Kultivierung des Militärgeistes war die Hauptaufgabe der deutschen Kaiser und Kanzler, die André François-Poncet wie folgt beschrieb: »il s'agit de rendre en quelque sorte conscient à lui-même l'orgueil national allemand - de développer partout le sens de la discipline, d'habitude de recevoir d'en haut une consigne qu'on exécute ponctuellement - et d'empêcher que l'esprit critique ne s'attaque à l'idée guerrière ${ }^{25}$. Dieses Programm werde in einer »campagne d'éducation patriotique « in erster Linie in den Schulen umgesetzt, wie André FrançoisPoncet aus eigener Erfahrung zu wissen glaubte:

Il faut avoir vu les bambins de l'école primaire défiler au pas de cadence, pour entrer dans leurs classes, sous l'œil dur du »Schulmeister« et se découvrir d'un geste mécanique, et déjà raide, lorsqu'ils arrivent à trois pas du maître, pour comprendre comment l'esprit militaire prussien a su gagner si rapidement toute l'Allemagne ${ }^{26}$.

Zur systematischen Verbreitung des Militärgeistes im wilhelminischen Kaiserreich trügen sämtliche Sozialisationsinstanzen in Deutschland, von der Schule bis zur Universität, von der Fabrik bis zum Geschäft, bei. Angesichts der systematischen Verbreitung des Militarismus kam André François-Poncet $1911 \mathrm{zu}$ dem Schluß, daß in Deutschland »tout existe en vue de la guerre, tend à la guerre, prépare la guerre«. Er erkannte im wilhelminischen Reich »une des plus formidables et des plus complètes organisations guerrières, qui ait sans doute jamais été mise sur pied ${ }^{27}$. Über diese Gefahr sollte sich keiner Illusionen machen. Vielmehr sei die militärische Vorbereitung, defensiv, wie André François-Poncet betont, eine lebenswichtige Notwendigkeit. Der 24jährige wollte zwar keinesfalls das deutsche Beispiel nachahmen, »mais il ne faut pas hésiter à développer chez nous la conscience calme et réfléchie de ce que nous sommes, de ce qu'est notre patrie, des liens qui nous y attachent et par la comparaison avec les autres pays des raisons que nous avons à défendre ${ }^{28}$. Deshalb rief er seine Zuhörer auf: »Soyons donc publiquement et résolument militaires, militaires à la française c'[est]-à-d[ire] avec cette bonne

Ibid. S. $2 \mathrm{v}$.

Ibid. S. 3r.

25 Ibid. S. 3v.

26 Ibid. S. 6r.

27 Ibid. S. $8 \mathrm{v}$.

28 Ibid. S. 10r. 
humeur, cette souplesse qui fait défaut aux Allemands, avec cet esprit de blague même et ce sourire qui n'est que la preuve des convictions fortes ${ }^{29}$.

Der im Frühjahr 1911 gehaltene Vortrag »L'esprit militaire des Allemands« enthielt schon alle Elemente des Deutschlandbildes André François-Poncets: Der an sich friedliebende, sympathische Durchschnittsdeutsche wurde von den preußischen Reformern militarisiert, indem diese den latenten Hochmut der Deutschen weckten und auf das Militärische konzentrierten. Der so entwikkelte »Militärgeist« werde im wilhelminischen Kaiserreich systematisch gepflegt, so daß ganz Deutschland auf einen möglichen Krieg ausgerichtet sei. André François-Poncet aktualisierte mithin nicht nur das während des deutschfranzösischen Krieges von dem Philosophen Caro entwickelte dichotome Deutschlandbild der Franzosen ${ }^{30}$, das moralisch Gut und Böse, geographisch Deutschland und Preußen und historisch Alt und Neu gegenüberstellte, sondern fügte diesem doppelten Deutschlandbild eine weitere Dimension hinzu, die soziologisch zwischen oben und unten unterschied. Das von André François-Poncet vor dem Ersten Weltkrieg erweiterte und vertiefte Wahrnehmungsklischee der zwei Deutschland ${ }^{31}$ blieb, wie wir sehen werden, bis ins hohe Alter die Grundlage für seine Deutschlandperzeption und -interpretation. Ende Oktober 1944 notierte er in sein Tagebuch:

Il y a bien deux Allemagnes, mais l'une, celle dont la culture avait gagné l'estime et la sympathie de l'univers, est de plus en plus refoulée, écrasée, submergée par l'autre qui marche à la remorque de la Prusse et sacrifie aux idoles païennes de la force, de la guerre, de l'orgueil de race et de la volonté de puissance. Je l'avais déjà noté en 1913. Depuis lors, le phénomène a pris les proportions d'une calamité mondiale ${ }^{32}$.

In diesem Sinne hatte er schon 1934 den Nationalsozialismus als Sieg der »Boches « über die »Allemands « charakterisiert ${ }^{33}$. Und der scheidende Hochkommissar schrieb Anfang Mai 1955 in seinem Abschlußbericht an das französische Außenministerium über die erste Bundeskanzlerwahl im September 1949: „C'est à une voix de majorité seulement que M. Adenauer l'avait emporté sur son rival, le social-démocrate Schumacher. Entre les deux

30 Siehe Beate GÖDDE-BAUMANNS, "Zwei Deutschlands« - aber ein Staat. Über eine alte französische Idee, in: Dokumente. Zeitschrift für den deutsch-französischen Dialog 43 (1987) S. 445-453. Vgl. auch Claude DIGEON, La crise allemande de la pensée française (1870-1914), Paris 1959, S. 57ff. und zu Caro S. 158ff.

31 André François-Poncet illustrierte sein Verständnis von der gängigen Formel der »deux Allemagnes « in einem Aufsatz, den er unter dem Titel "Les deux Allemagne« [sic!] im März 1914 in der von ihm mitgegründeten »Revue politique internationale« veröffentlichte, vgl. DERS., Les deux Allemagne, in: Revue politique internationale 1 (1914) S. 266-278. »Allemagne« steht nicht im Plural, wie Annette MESSEMER fälschlicherweise schreibt, vgl. DIES., François-Poncet, S. 508.

32 André FRANÇOIS-PONCET, Camets d'un captif, Paris 1952, S. 255.

33 Zitiert in Friedrich MENECKE, Ausgewählter Briefwechsel. $\mathrm{Hg}$. und eingeleitet von Ludwig DEHIO und Peter CLASSEN, Stuttgart 1962, S. 347 f. 
hommes, le destin avait paru hésiter, comme entre deux Allemagnes ${ }^{34}$. Je nachdem welche Seite Deutschlands er im Blick hatte bzw. er zur Interpretation und Konzeption zugrunde legte, änderten sich seine deutschlandpolitischen Vorstellungen: Vor dem Ersten Weltkrieg genossen, wie gesehen, in erster Linie die preußisch-kriegerischen Elemente Deutschlands seine Aufmerksamkeit, so daß die deutsch-friedliche Seite in den Hintergrund trat. Infolgedessen plädierte André François-Poncet, wie gesehen, für die Nachahmung des deutschen Beispiels, das damit auch Vorbild war. Insofern blieb, wie noch zu zeigen sein wird, bis in die 20er Jahre hinein eine konfrontative Einstellung gegenüber Deutschland maßgebend, die zeit seines Lebens, wenn in seiner Wahrnehmung die negativen Elemente den Vorrang gewannen, reaktivierbar war.

André François-Poncet nahm zwei Jahre später den Vortrag von 1911 - in sprachlich leicht überarbeiteter Form - als erstes Kapitel in sein Buch über das Denken der deutschen Jugend auf: "L'Allemagne, machine de guerre $\aleph^{35}$. Erweitert wurde die Darstellung um mehrere Kapitel über die studentische Jugend in Deutschland, die er auf einer zweiwöchigen Reise Anfang April 1913 untersuchte. Ausgangspunkt war die Frage, ob die Deutschen von morgen denen von heute folgen oder ob sie ein neues Deutschland vorbereiteten ${ }^{36}$. Trotz seiner Sympathie für »l'Allemagne intellectuelle et artistique d'hier et d'aujourd'hui « glaubte André François-Poncet keine Spuren »d'un prochain changement d'attitude« bei den Deutschen feststellen zu können. Angesichts dieser Feststellung müsse er auf seinen »Herzenswunsch « verzichten und den Realitäten ins Auge schauen: "La conception fondamentale de l'Allemagne est celle d'un état militaire ${ }^{37}$. Alles strebe in Deutschland zur Armee. "Demain ce sera la même chose. Je prétends que ce sera pire ${ }^{38}$. Vor diesem Hintergrund gewann in den Augen André François-Poncets die deutsche Heeresvermehrung von 1913 erst ihr eigentliches Gewicht. Denn hinter den 200000 zusätzlichen Soldaten sah François-Poncet ein ganzes Volk. Der 26jährige verlangte infolgedessen von Frankreich eine moralische und materielle Aufrüstung nach deutschem Vorbild, um für eine mögliche Auseinandersetzung gewappnet zu $\operatorname{sein}^{39}$. Nicht daß der Autor und seine Landsleute einen Krieg mit Deutschland wollten, sie wollten aber auch keinen Frieden, der Frankreich Deutschland bzw. die Franzosen den Deutschen unterordne: »La pax germa-

34

35 FRANÇOIS-PONCET, Jeunesse, S. 13-32.

36 Ibid. S. 10.

37 Ibid. S. 109. Das ist gleichzeitig der erste, versteckte Hinweis auf einen Verständigungswunsch bei André François-Poncet.

38

39

Ibid. S. 111. Der Kritik, daB »un état militaire « nicht notwendigerweise »un état guerrier» sein müsse, war André François-Poncet nicht zugänglich: "il me semble qu'un état militaire est plus facilement guerrier qu'un autre«.

Ibid. S. 113f. 
nica [Hervorhebung im Original, cws], imposée par les armes, implique une reconnaissance de la suprématie allemande. Nous ne pouvons l'admettre, et plus nous serons des intellectuels, moins il nous sera possible de l'admettre $\ll^{40}$. Vor diesem Hintergrund stand André François-Poncet deutsch-französischen Verständigungsversuchen skeptisch gegenüber. »Nous ne pourrons pas nous entendre «, schrieb er in Hinblick auf die deutsch-französische Parlamentarierkonferenz in Bern vom Frühjahr $1913^{41}$. Diese Haltung erläuterte er in einem Brief an die Zeitschrift Correspondance, die ihn unter dem Titel "Le rapprochement franco-allemand« am 15. Januar 1914 veröffentlichte ${ }^{42}$ :

On rencontre dans la vie assez de gens que leurs convictions intimes opposent les uns aux autres en dépit de la sympathie personnelle qui les rapproche. Le cas franco-allemand me semble analogue. À l'heure actuelle, je n'aperçois aucun moyen de conciliation qui ne suppose d'un côté ou de l'autre un certain renoncement à soi-même, et rien n'indique que, d'une part ou de l'autre, on y soit disposé $e^{43}$.

Die deutsch-französischen Gespräche werden vielleicht mit einer Umarmung enden: »Ce ne pourra être qu'un baiser Lamourette, et ceux qui s'y seront prêtés, avec plus de généreuse ardeur que de prudente réflexion, en conserveront une rancune qui augmentera pour l'avenir les chances de conflit $\ll^{44}$. Die Konfliktmöglichkeiten lagen für André François-Poncet nicht nur im ElsaßLothringen-Problem, sondern vor allem im »impérialisme allemand « und in der »expansion allemande et l'accroissement méthodique de son appareil guerrier«. Deutschland könne nicht verboten werden zu wachsen und seine Kräfte zu sammeln. »Elle les accumule, non pas contre nous, ni contre tels ou tels autres [...]. Elle les accumule pour le principe, pour obéir à sa loi intérieure, à l'entraînement de sa prospérité même -, et aussi, sans doute, pour s'en servir au besoin «. Eine solche (Vor)Macht reduziere notwendigerweise die anderen Staaten zu Satelliten oder gruppiere sie in gegnerische Blöcke. "Il ne peut plus s'agir d'être au niveau; il faut être au-dessous, ou au-dessus « ${ }^{45}$. Vor diesem Hintergrund warnte André François-Poncet vor einer Verständigung mit Deutschland, da sie für ihn einer Selbstaufgabe gleichkam, die mit der Anerkennung der deutschen Überlegenheit und dem Eintritt in seinen Bannkreis verbunden $\operatorname{sei}^{46}$. Infolgedessen hielt er auch die laufenden Verständigungsversuche für »ingénus et dangereux “ ${ }^{47}$.

${ }^{40}$ Ibid. S. 114f.

${ }^{41}$ Ibid. S. 85. Zu den Verständigungsversuchen vor dem Ersten Weltkrieg siehe CompteRendu de la Conférence Interparlementaire franco-allemande tenue à Berne, Bern 1913. Zur Aufnahme in Frankreich siehe ZIEBURA, Deutsche Frage, S. 141-157.

${ }^{42}$ Correspondance vom 15. Januar 1914, S. 196-201.

43 Ibid. S. 197.

44 Ibid.

45 Ibid. S. 199.

46 Ibid.

47 Ibid. S. 200. 
Angesichts der gezeigten Einschätzung des wilhelminischen Deutschlands dürfte André François-Poncet der Ausbruch des Ersten Weltkrieges nicht überrascht haben ${ }^{48}$. Im August 1914 mobilisiert, führte der 27jährige zunächst als sous-lieutenant, ab 1915 als lieutenant die 20. Kompanie des 304. Infanterieregiments in Kämpfen an der Meuse und in der Woëvre. Die Kriegserfahrungen führten indes zu keiner Veränderung im dichotomen Deutschlandbild André François-Poncets. Am 6. Mai 1915 schrieb er an André Viénot:

Quant aux Boches, je n'ai jamais pensé qu'on peut réduire à merci, et déferler ensuite à loisir une telle nation, fanatisée depuis un $1 / 2$ siècle [sic]. Leur donner un rude coup sur les doigts et une leçon qui ouvrira quelques-unes de leurs idées, sera déjà un fameux résultat. Au reste, et aussi je vais vous paraître scandaleux, j'affirme encore que Goethe est un grand homme, Wagner, Nietzsche et quelques autres aussi ${ }^{49}$.

Die bleibende Hochachtung vor der deutschen Kultur und ihrer Repräsentanten verband sich während des Krieges mit dem üblichen Respekt vor den Leistungen der gegnerischen Soldaten und vor dem Durchhaltewillen des deutschen Volkes. »La résistance allemande doit dépasser, à mon sens, les estimations courantes«, schrieb er seinem Studienfreund René Massigli am 2. März $1915^{50}$. Der Erhalt der positiven Einstellung gegenüber den Deutschen ist bemerkenswert, weil der junge Offizier durchaus die Schrecken des Krieges in vorderster Front kennenlernte: »Il faut t'imaginer«, schrieb er im gleichen Brief vom 2. März 1915, »notre état d'atonie, de harassement, après des mois, et plus, de cette garde dans des trous d'eau et de boue [...]. On devient un végétal triste, accroché au flanc d'une colline, occupé à disputer sa vie aux éléments «. Nach der Verlegung seiner Einheit an einen anderen Frontabschnitt an der Woëvre schrieb er im Sommer 1915: »je dois, jusqu'à nouvel ordre, me considérer comme mort, du moins comme mourant; ici, il y a chaque jour beaucoup de tués et de blessés « ${ }^{51}$. Angesichts dieser Erfahrung schrieb er am 20. Dezember 1915 an René Massigli:

Vgl. auch den Artikel in der Zeitung »Le Républicain du XIV ${ }^{e}$ « vom 1. April 1914, S. 2f., in: AN/AP 462, 2: André François-Poncet kritisierte - vor dem Hintergrund des Friedens von Bukarest, der den zweiten Balkankrieg beendete - die Aufhebung der dreijährigen Dienstpflicht: »La guerre, à peine éteinte dans les Balkans, y va renaître demain«.

49 AN/AP 462, 3. Viénot schickte François-Poncet, »mon cher Ami «, am 23. Juli 1962 den Brief mit der Bermerkung zurück: »Elle [la lettre] contient des vues qui, à l'époque, n'étaient pas celles des Bourgeois français moyens«, in: ibid. Diese Einschätzung stimmt, vgl. Klaus HEITMANN, Das französische Deutschlandbild in seiner historischen Entwicklung (II), in: Sociologia internationalis 4 (1966) S. 165-195, hier S. 165ff.

50 AMAE, PA-AP 217, Vol. 97, S. 184. In dem im Archiv des französischen Außenministeriums aufbewahrten Nachlaß von René Massigli finden sich vier Feldpostbriefe von André François-Poncet aus den Jahren 1914/1915, ibid. S. 183-188.

51 Ibid. S. 185f. Der Brief ist undatiert. Er muB aber aufgnund seines Inhalts zwischen Frühjahr (Schreiben vom 2. März) und Winter (Schreiben vom 20. Dezember) 1915 geschrieben worden sein. 
Enfin, tu sais, nous y passerons tous. Il est impossible que la guerre épargne ceux qui la pratiquent depuis longtemps. Les derniers arrivés survivront peut-être. Mais le risque quotidien, même dans les longs mois d'accalmie, est tel qu'un moment arrive où la nécessité mathématique couche, l'un après l'autre, les anciens combattants ${ }^{52}$.

André François-Poncet entging der »Notwendigkeit«, weil er im Januar 1916 dem Außenministerium zur Verfügung gestellt wurde ${ }^{53}$. Als "attaché à titre temporaire « kam der Germanist ins bureau de presse der Botschaft in Bern, um die deutschsprachigen Zeitungen auszuwerten ${ }^{54}$. Aus der Schweiz kehrte er im Frühjahr 1919 zurïck.

Trotz der friedlichen Jahre in Bern stürzten die Fronterfahrungen André François-Poncet nach dem Krieg in eine schwere Identitätskrise: »L'homme qui s'assied à cette table est-il bien le même homme? Qu'ai-je encore de commun avec celui qui sortait ici, le 4 août 1914 «, notierte er am 28. März 1919, dem Tag seiner Rückkehr nach Paris ${ }^{55}$. Der Rückkehrer wünschte nichts mehr, als in Schlaf und Vergessen zu versinken: »Je voudrais jouer à des jeux faciles, m'étendre aux pieds d'une femme aimable et fermer les yeux " ${ }^{56}$. Auslöser der Krise war neben den Kriegserfahrungen wohl der Tod seines jüngsten Bruders Anfang Juni $1918^{57}$ : »La matière que je rapporte m'écrase et m'étouffe. Je ne me sens pas capable de la dominer. Est-ce un devoir pour ceux qui rentrent de fixer pour ceux qui ne sont pas partis et pour ceux qui naîtront après eux ce qu'ils ont retenu de leurs aventures? ${ }^{58}$ Das hätten schon Hunderte Schriftsteller gemacht und außerdem interessiere sich niemand für die Erfahrungen der Veteranen, versuchte er sich zu entschuldigen. Sein Gewissen sagte ihm aber,

que je représente mes amis morts, mon frère mort dont la pensée revit en moi et que je dois des comptes à ces ombres qui m'environnent. Chers amis morts, cher enfant disparu, je me sens lâche et fatigué. Donnez-moi un peu de votre jeunesse éternelle afin que je résiste à la

52 Ibid. S. $187 \mathrm{v}$.

53 Die Hintergründe dieser Berufung bleiben im dunkeln. Fest steht, daß René Massigli seit Kriegsausbruch im Generalstab diente und mit André François-Poncet ins Pressebüro der Botschaft in Bern abkommandiert wurde. Angesichts des alarmierenden Briefes seines Freundes vom 20. Dezember 1915 und der gemeinsamen Versetzung wenige Wochen später, kann angenommen werden, daB René Massigli sich für den Studienfreund eingesetzt hat. Ein diese Annahme stützender Beleg konnte nicht gefunden werden. Siehe zu der Mission Henning KÖHLER, Novemberrevolution und Frankreich. Die französische Deutschlandpolitik 1918-1919, Düsseldorf 1980, S. 273.

$\mathrm{Zu}$ den einzelnen Verwendungen und den Aufgaben in Bern siehe AN/AP 462, 3.

55 André FRANÇOIS-PONCET, Réflexions d'un revenant, in: AN/AP 462, 4, hier S. 4.

56 Ibid.

57 Maxime François-Poncet (*12. März 1898) fiel in der letzten Offensive der deutschen Truppen. André François-Poncet widmete dem Bruder eine einfühlsame Hommage, die in der Anthologie des écrivains morts à la guerre 1914-1918, Bd. 1, Amiens 1924, S. 550 551, mit einem Gedicht aus dessen Feder veröffentlicht wurde.

58 André FRANÇOIS-PONCET, Réflexions d'un revenant, in: AN/AP 462, 4, hier S. 4. 
première tentation qui sollicite ceux qui reviennent et ne plus s'en faire et n'être plus que des spectateurs philosophes 59 !

Diese Überlegungen markieren die Wende im Leben von André FrançoisPoncet: Der 32jährige wollte nicht mehr nur "philosophischer Betrachter" sein, wie er das vor dem Krieg gewesen war. Sicher, der Deutschland-Kenner hielt 1919 eine Reihe von Vorträgen über die Entwicklung in Deutschland ${ }^{60}$, aber diese wissenschaftlich-publizistische Beschäftigung erschien ihm angesichts der Kriegserfahrung als ungenügend. Schon an der Front sei er mit Problemen konfrontiert worden, die er vorher nicht gekannt hatte:

Je me rendais compte que, moi et mes pareils, nous prétendions philosopher sans avoir eu contact avec les réalités les plus urgentes de la vie. Je n'avais pas perdu le goût des lettres ni des arts. Je le considérais désormais comme un luxe, auquel il n'était plus permis de sacrifier, avant d'avoir aidé notre pays à retrouver une assiette, une sécurité, un bien-être ${ }^{61}$.

André François-Poncet war überzeugt, daß nach dem Krieg wirtschaftliche Fragen im Vordergrund stünden, und er hatte den Wunsch, sich ihnen in der Industrie oder im Handel zu widmen. Er wollte das »bain de realisme« nicht mehr verlassen, sondern in der Realität bleiben und sich nützlich machen ${ }^{62}$. Anknüpfungspunkte waren gegeben: André François-Poncet hatte sich schon vor dem Krieg im cercle républicain démocratique du $14^{\mathrm{e}}$ arrondissement engagiert und eigenhändig dessen Statuten redigiert ${ }^{63}$. Eine politische Karriere schien möglich. Außerdem bestanden über seine Mutter Verbindungen zu Robert Pinot, dem einflußreichen Generalsekretär des französischen Schwerindustriellenverbandes. André François-Poncet hatte ihn in Genf persönlich kennengelernt ${ }^{64}$. Wenige Monate nach dem Waffenstillstand bot Pinot ihm an,

Ibid. S. 4f. Siehe auch FAURE, Discours, S. 20. Michel Espagne meint, »que le décès de son frère cadet à la guerre de 14 impliquait pour lui, au-delà des approches intellectuelles, une autre relation existentielle à l'Allemagne«, in: Michel ESPAGNE, Les germanistes français à l'École Normale, in: Michel ESPAGNE (Hg.), L'École Normale Supérieure et l'Allemagne, Paris 1995, S. 208.

${ }^{60} \mathrm{Vgl}$. die verschiedenen Manuskripte im Nachlaß, AN/AP 462, 4. Siehe auch André FRANÇOIS-PONCET, La révolution en Allemagne et la situation actuelle, Paris 1918.

61 André FrançOIS-PONCET, Pinot, S. 267f.

${ }^{62}$ Ibid. S. 268.

${ }^{63}$ Das vierseitige Manuskript des »Projet de Statuts rédigé par André François-Poncet« findet sich im Nachlaß, AN/AP 462, 2. Eine stark gekürzte Fassung erschien auf der Titelseite von »Le Républicain du XIV « am 1. April 1914, in: ibid.

${ }^{64}$ Über die Verbindungslinien und die Begegnung liegen widersprüchliche Berichte vor: André François-Poncet gibt an, Robert Pinot Ende 1917 kennengelernt zu haben, siehe FRANÇOIS-PONCET, Pinot, S. 266. Roselyn Solo siedelte - wohl aufgrund ihrer Gespräche mit André François-Poncet - die Begegnung einige Monate nach Kriegsende an. Die Bekanntschaft rührte nach ihrer Darstellung von seiner Mutter her, vgl. SOLO, Ambassador, S. 11. BENOIT, Réponse, S. 117, FAURE, Discours, S. 20, BOCK, Rapports, S. 128ff., DERS., Skizze, S. 382f. und DERS., Perzeption, S. 588f. sowie MESSEMER, François-Poncet, S. 509 f. machen zu der Begegnung keine näheren Angaben. 
einen »service d'information « für das Comité des forges zu organisieren ${ }^{65}$. $\mathrm{Daß}$ der 32jährige das Angebot annahm, liegt auf der Hand. Schließlich suchte er eine Beschäftigung, die ihn mit der Wirtschaftswelt in Verbindung brachte.

Aufgrund der Kriegserfahrungen veränderte André François-Poncet auch seinen Blick auf Deutschland. Dies macht seine Distanzierung von der "génération d'Agathon « deutlich, zu der ihn die Forschung teilweise heute noch rechnet ${ }^{66}$. Diese Zurechnung basiert auf einem Beitrag des 26jährigen zu der 1913 unter dem Pseudonym »Agathon« veröffentlichten Untersuchung "Les jeunes gens d'aujourd'hui « ${ }^{67}$. André François-Poncet glaubte zwar, wie die Autoren, daß eine neue Generation auszumachen sei. Er unterschied aber diese Generation nicht, wie die Untersuchung, von der Generation der um 1870 Geborenen, sondern von seiner, also der um 1890 Geborenen: "Je veux croire, je crois comme vous, que la jeunesse d'aujourd'hui diffère de ce que nous étions hier, et qu'elle s'en distingue notamment par un sens impérieux de l'action, une médiocre estime de l'intellectualisme, un goût marqué par des fins pratiques, une foi vivace dans l'avenir de la patrie, enfin par son culte passionné du sport « ${ }^{68}$. André François-Poncet grenzte in seinem Beitrag also, salopp formuliert, die Twens von den Teenies der Zeit ab. »Aujourd'hui, mon jeune frère, de dix ans plus jeune que moi, m'entraîne, le dimanche, à des matches de rugby, au Parc des Princes, où il retrouve toute sa classe ${ }^{69}$. Der 26jährige zählte mithin nicht sich, sondern seinen 15jährigen Bruder Maxime zu der neuen Generation, die für die Autoren der Studie gleichwohl die um 1890 Geborenen, also die Generation Andrés, waren. $\mathrm{Zu}$ diesem Mißverständnis zwischen André François-Poncet und Agathon kommt die verwirrende Zweideutigkeit der Studie, die Jean-Jacques Becker in seiner Einleitung wie folgt beschreibt: »Il prétend décrire la pensée de demain, mais il écrit de telle façon qu'il la présente comme celle d'aujourd'hui. Il dit une chose et il en fait une autre. Néanmoins, une lecture plus serrée porte un coup sévère à ceux qui ont cru pouvoir dire, après avoir lu Agathon, voilà comment

65 FrançoIs-PonCET, Pinot, S. 268.

${ }^{66}$ So BoCK, Rapports, S. 131. Daß André François-Poncet keine "Agathon «-Positionen vertrat, ist eigentlich seit Mitte der 60er Jahre bekannt, siehe Jacques DROZ, Les relations franco-allemandes intellectuelles de 1871 à 1914, Paris 1966, S. 63f.

67 Agathon [Henri Massis, Alfred de Tarde], Les jeunes gens d'aujourd'hui, Paris ${ }^{2} 1995$. Die Untersuchung erschien 1912 als Artikelfolge in der Zeitschrift "L'opinion « und 1913 um »Témoignages« erweitert als Buch. Die historischen Sozialwissenschaften in Frankreich haben schon früh auf die methodischen Mängel und der daraus folgenden bedingten Aussagekraft der Studie verwiesen. Vgl. Jean-François SIRINELLI, Génération intellectuelle. Khâgneux et normaliens dans l'entre-deux-guerres, Paris 1988, S. 226ff. und die Einleitung Jean-Jacques Beckers zum Nachdruck der Untersuchung 1995, AGATHON [Henri Massis, Alfred de Tarde], Les jeunes gens, S. 7-39, insbesondere 12ff. Diese Kritik wurde in Deutschland noch nicht aufgenommen.

69 Ibid. S. 186. 
était la jeunesse de cette époque « ${ }^{70}$. Angesichts des Mißverständnisses mit Agathon und der Mißverständlichkeit der Studie ist eine Einordnung André François-Poncets in die "génération d'Agathon « mehr als bedenklich, auch wenn, wie zu zeigen sein wird, Charakteristika dieser Generation bei ihm nachzuweisen sind ${ }^{71}$. Außerdem hatte er sich schon im Ersten Weltkrieg von der »génération d'Agathon « distanziert ${ }^{72}$. Die Abkehr wurde im Spätjahr 1915 offensichtlich, als seine Einheit an der Woëvre täglich Verluste zu beklagen hatte. Der Kompanieführer schrieb an René Massigli:

à ces moments-là, dans les opéras, on chante; dans la réalité, on se tient coi [...] et on attend; cette allégresse qui se précipite sur l'encrier ne se rencontre, en pareil cas, que chez les jeunes amis de Barrès, dont la plupart est, sans doute, conducteur d'automobile, cycliste, brancardier, divisionnaire ou secrétaire d'état. [...] Car il y a front et fronts, et sur le vrai front, la littérature ne pousse pas $^{73}$.

Den großsprecherischen Freunden Barrès stellte André François-Poncet den einfachen Soldaten gegenüber. "Le vrai poilu parle peu et ne se vante pas; jamais il ne fait fort d'exterminer son ennemi; sa devise est >Rien à signaler<. Nul ne sait mieux que lui la gravité du temps présent, la difficulté de l'avenir, et que, malgré tous les fanfarons, la guerre reste une chose terrible, à quoi l'on ne s'habitue pas $\aleph^{74}$. Angesichts der deutlichen Distanzierung von der »génération d'Agathon « und der schweren Krise, die André François-Poncet nach dem Ersten Weltkrieg durchlitt, ist er vielmehr der "génération de guerre « zuzurechnen, zu der er sich Mitte der 20er Jahre auch selbst bekannte ${ }^{75}$. Die

70 Vgl. Einleitung Jean-Jacques Beckers zum Nachdruck der Untersuchung 1995, AGATHON [Henri Massis, Alfred de Tarde], Les jeunes gens, S. 13.

71 Der die "génération d'Agathon « auszeichnende »foi patriotique« und "réalisme politique« war dem späteren Botschafter durchaus eigen. Der an erster Stelle stehende "goût d'action « der »neuen Generation « war wohl nicht seine Sache, zumindest finden sich in dem untersuchten Lebensabschnitt keinerlei Hinweise auf eine sportliche Betätigung. Eine »renaissance catholique « ist ebenso wenig festzustellen: »Pour moi, « bekannte André François-Poncet zwar 1925, »qui n'ai rien d'un clérical, ni même d'un catholique pratiquant, $\mathrm{j}$ 'avoue que l'anticléricalisme provoque en moi une répulsion presque physique«. Aus dieser Ablehnung des Antiklerikalismus auf eine persönliche Religiosität zu schließen, ist absurd. Folge war vielmehr sein Eintreten für den Laizismus, vgl. André FRANÇOIS-PONCET, Réflexions d'un républicain modeme, Paris 1925, S. 109ff.

72 Die Meinungsverschiedenheiten zeichneten sich bei Kriegsbeginn ab, vgl. André FrANCOIS-PONCET, Réflexions d'un revenant, in: AN/AP 462, 4, S. 2. Der Heimkehrer erinnerte sich an den Abschiedsbesuch von »Agathon« am Tag nach der Kriegserklärung: »Vous étiez remplis de gaieté et d'ardeur. Vous disiez: >On va bien voir! Ça ne pouvait pas durer! L'Angleterre marche! ‘ Et moi, j'étais muet et glacé. Vous en étiez déçus. Je haussais les épaules et je disais: >Vous ne connaissez pas l'Allemagne! Vous [unleserlich, cws] de quoi elle est capable. Cette guerre est une aventure! « AMAE, PA-AP 217: Massigli, Vol. 97, S. 185r.

74 Ibid. S. $185 \mathrm{v}$.

75 FRANÇOIS-PONCET, Républicain moderne, S. 17. Diese Einschätzung bestätigt Armand Bérard, der langjährige Mitarbeiter André François-Poncets in Berlin und auch in Bonn, siehe BÉRARD, Ambassadeur, Bd. I, S. 109. 
Kriegserfahrungen hatten für ihn ein größeres biographisches Gewicht als die Vorkriegserfahrungen. Diese Richtigstellung hat nicht nur akademische, sondern auch heuristische Bedeutung. Denn die Kriegserfahrungen wirkten sich auf die deutschlandpolitischen Vorstellungen André François-Poncets aus, die sich durch weitere Einflüsse, die im folgenden zu beschreiben sind, in ihrer Akzentuierung deutlich veränderten. Gleichwohl hatte André François-Poncet das Grundmuster seines dichotomen Deutschlandbildes - wie gesehen - schon vor dem Ersten Weltkrieg festgelegt. Er hat indes im Laufe seines Lebens dieses Bild je nach Anlaß bzw. Situation unterschiedlich aktualisiert und damit auch verschieden akzentuiert. Das Grundmuster blieb jedoch gleich.

\subsection{Für eine Annäherung}

Die Neuakzentuierung der deutschlandpolitischen Vorstellungen André François-Poncets in den Jahren nach dem Ersten Weltkrieg wurde maßgeblich von Robert Pinot und dem französischen Schwerindustriellenverband beeinflußt, dem sich der 31 jährige angeschlossen hatte. Der Generalsekretär des Verbandes wünschte für das Comité des forges »une information plus vivante, plus rapide, moins spécialisée« und betraute den Kriegsheimkehrer mit dieser Aufgabe $^{76}$. André François-Poncet übernahm mit zwei Kollegen aus Bern die Redaktion eines »Bulletin quotidien «, in dem »à côté des problèmes proprement métallurgiques, et sur la base d'un large dépouillement des journaux de tous les pays, étaient résumées et commentées les questions d'intérêt général, économique, social et politique, tirées de l'actualité la plus immédiate ${ }^{77}$. Das Blattkonzept hatte Erfolg. Die Verbandszeitschrift weckte das Interesse eines über die Mitgliedschaft hinausgehenden Publikums, so daß sie nach einem Jahr in die Unabhängigkeit entlassen wurde: Die Société d'Études et d'Informations économiques gab ab Mai 1920 das Bulletin heraus, als Chefredakteur zeichnete André François-Poncet, der auch Direktor der Aktiengesellschaft war $^{78}$. Trotz der organisatorischen und auch örtlichen Trennung vom Schwerindustriellenverband - die 15 Redakteure bezogen Räume am Boulevard Saint-Germain - galt und gilt das Bulletin als »une émanation directe du

FRANÇOIS-PONCET, Pinot, S. 265. Im Auftrag bzw. als Repräsentant des Comité des forges war er im August 1919 auf einer »Mission en Allemagne« und im Oktober 1919 auf einer "Mission économique française aux États-Unis«. Zum Comité des forges vgl. Robert PiNot, Le Comité des forges de France au service de la Nation, Paris 1919, insbesondere Kapitel I.

77 FRANÇOIS-PONCET, Pinot, S. 268f.

78 Ende Mai 1920 heiratete André François-Poncet Mlle Jacqueline Dillais, so daß die ihn ein Jahr zuvor erfassende Lebenskrise als überwunden gelten kann. 
Comité des forges « ${ }^{79}$. Demgegenüber betonte André François-Poncet immer wieder die »indépendance absolue« der Aktiengesellschaft und »que le Comité des forges ne lui a jamais versé de cotisation ou de souscription ${ }^{80}$. Trotzdem ist eine starke Kongruenz der Vorstellungen von Comité und Société unübersehbar, wie zum Beispiel ihre neo-liberal-korporatistische Argumentation in der Frage des 8-Stunden-Tages zeigt ${ }^{81}$. Unter dem Einfluß des Schwerindustriellenverbandes und vor allem seines Generalsekretärs stand insbesondere André François-Poncet, der als Germanist von wirtschafts- und sozialpolitischen Problemen bisher vollkommen unberürt geblieben war. Er hatte sich ja, wie gezeigt werden konnte, vor dem Weltkrieg einen Namen nur als außenund insbesondere deutschlandpolitischer Experte gemacht. Infolgedessen übernahm André François-Poncet in weiten Teilen die Vorstellungen des Schwerindustriellenverbandes und insbesondere die von Robert Pinot, die aber bei der aufgeworfenen Fragestellung nicht im einzelnen dargelegt werden müssen ${ }^{82}$. Zu zeigen sein wird vielmehr, wie er seine außen- und deutschlandpolitischen Vorstellungen unter diesem Einfluß modifizierte.

Anfang der 20er Jahre verstärkte André François-Poncet auch sein politisches Engagement, das nicht ohne Einfluß auf seine deutschlandpolitischen Vorstellungen blieb. Hatte sich der 26jährige 1913 noch als parteipolitisch ungebunden bezeichnet ${ }^{83}$, so wirkte er schon 1914 in einem "Cercle républicain démocratique du $14^{\mathrm{e}}$ arrondissement $\mathrm{mit}^{84}$. Nach seiner Rückkehr

Claude Bellanger, Jacques Godechot, Pierre Guiral, Femand Terrou (Hg.), Histoire générale de la presse française, Bd. III: De 1871 à 1940, Paris 1972, S. 494.

${ }^{80}$ FRANÇOIS-PONCET, Pinot, S. 271.

81 Ibid. S. 274-286 und André FranÇOIS-PONCET, Émile MIREAUX, La France et les Huit Heures, Paris 1922.

${ }^{82}$ Siehe André FRANÇOIS-PONCET, Une formule nouvelle: le contrôle syndical, Paris 1921 und DERS., MIREAUX, La France et les Huit Heures sowie FranÇOIS-PONCET, Pinot.

${ }^{83}$ FRANÇOIS-PONCET, Jeunesse, S. 10. Als ENS-Student gehörte er gleichwohl der »ligue patriotique des étudiants républicains« an, die sich Schlägereien mit der monarchistischen Action française vor der Sorbonne lieferte. Vgl. auch Journal officiel 1925, Chambre des députés, $2^{\mathrm{e}}$ Séance du 31 mars 1925, S. 2007, in der André François-Poncet erklärte: "L'action de la ligue politique à laquelle j'appartiens est restée cantonnée sur un terrain tout à fait général «.

84 Schon mit der 1913 veröffentlichten Schrift über das Denken der deutschen Jugend unterstützte André François-Poncet - wie gesehen - die Forderung der französischen Rechten nach Einführung einer dreijährigen Dienstpflicht. Insofern stand er seit seinen ersten öffentlichen Äußerungen politisch auf seiten der gemäßigten Rechten, wie seine Sozialisation das erwarten ließ. Bock formulierte in Perzeption, S. 589 mißverständlich: "So wie sich in der Vorkriegszeit zentrale Elemente seines Deutschlandbildes ausformten, so festigte sich aufgrund der Weltkriegserfahrungen und Nachkriegseinflüsse sein politisches Weltbild«. Von einer sukzessiven Ausbildung eines außen- und dann innenpolitischen Weltbildes kann aber keine Rede sein. André François-Poncet entwickelte sein politisches Weltbild in den Grundzügen vor dem Ersten Weltkrieg, brachte aber, wie zu zeigen sein wird, seine Elemente zu unterschiedlichen Zeitpunkten unter- 
aus der Schweiz in der Alliance républicaine démocratique aktiv ${ }^{85}$, übernahm André François-Poncet nach deren Umwandlung in den Parti républicain démocratique et social 1919/1920 erste Parteiämter: Er wurde Mitglied des Comité directeur und der Commission de propagande. Auf die Mitte-RechtsGruppierung ${ }^{86}$, die aus der orléanistischen Tradition der französischen Rechten kommt und den modérés zuzurechnen ist, ging der Bloc républicain national zurück, der nach seinem Wahlsieg 1919 bis 1924 die französischen Regierungen stellte. Die politische Affinität zum Bloc national und die persönliche Bekanntschaft mit den Führern desselben führten André François-Poncet in die Nähe der Regierungskreise, die seine journalistischen Fähigkeiten und seine wirtschaftspolitischen Kenntnisse vor und während der Konferenz von Genua in Anspruch nahmen ${ }^{87}$. Ministerpräsident Raymond Poincaré, Nachfolger des über seine auf der Konferenz von Cannes (6. bis 13. Januar 1922) an Großbritannien gemachten Zugeständnisse gestürzten Aristide Briand, bat den Direktor der Société d'Études et d'Informations économiques, die französische Haltung zu der nach Genua einberufenen Weltwirtschaftskonferenz zusammenfassend darzustellen. Innerhalb einer Woche schrieben André François-Poncet und seine Kollegen einen fast 200 Druckseiten umfassenden Text, der ohne Veränderungen von Poincaré angenommen worden sein soll und auf der Konferenz von Genua (10. April-19. Mai 1922) unter den anwesenden Delegationen verteilt worden ist ${ }^{88}$. Die Abhandlung erschien

schiedlich zum Ausdruck. Die Grundlagen wurden indes vor dem Weltkrieg gelegt, anschließend wurden nur noch Ergänzungen oder Modifikationen vorgenommen.

${ }^{85} \mathrm{Vgl}$. Henry CostoN, Partis, Journaux et Hommes politiques d'hier et d'aujourd'hui, Paris ${ }^{2} 1987$, S. 518 und S. 545.

${ }^{86}$ Zur Einordnung der Gruppierung in die französische Parteienlandschaft und zu ihrem Programm siehe René REMOND, La droite en France de la première restauration à la $\mathrm{V}^{\mathrm{e}}$ République, Paris ${ }^{3} 1971$, Bd. 1: 1815-1940, S. 206ff. und Pierre LEVEQUE, Histoire des forces politiques en France, Paris 1994, Bd. 2: 1880-1940, S. 26-29 und S. 45-50. Vgl. auch Rudolf von ALBERTINI, Parteiorganisation und Parteibegriff in Frankreich 1789-1940, in: HZ 193 (1961) S. 582-585.

87 André François-Poncet war zumindest mit Raymond Poincaré persönlich bekannt, wie er in: Poincaré tel que je l'ai vu, in: Le Figaro littéraire vom 26. Juni 1948, S. 1 schreibt. Demnach hatte er Poincaré uiber Maurice Colrat kennengelernt, dem ehemaligen Direktor der Tageszeitung "L'Opinion «, der seit 1919 in der Abgeordnetenkammer saß und im Kabinett Poincarés Stellvertreter war, vgl. Dictionnaire de Biographie Française, Bd. 9, Paris 1960, S. 344. Als Mitarbeiter von "L'Opinion« kannte André François-Poncet natürlich Colrat, dem er seine Schrift »Ce que pense la jeunesse allemande« gewidmet hatte. Ministerpräsident Poincaré nahm nicht nur André François-Poncet, sondem weitere Redakteure des »Bulletin« zur Weltwirtschaftskonferenz nach Genua mit, vgl. den Brief François de Wendels an Robert Pinot vom 1. Mai 1922, zitiert bei Jean-Noël JEANNENEY, François de Wendel en République. L'argent et le pouvoir, 1914-1940, Bd. III, Paris 1976, S. 1005, Anm. 23.

88 So die Darstellung von André FrançoIS-PONCET, in: DERS., Poincaré tel que je l'ai vu, in: Le Figaro littéraire vom 26. Juni 1948, S. 1. 
unter dem Pseudonym »Celtus ${ }^{89}$ und dem Titel »La France à Gênes. Un programme français de reconstruction économique de l'Europe «" ${ }^{90}$. Die ohne Mitwirkung der zuständigen Ministerien erstellte Schrift reflektiert zumindest die Position des französischen Ministerpräsidenten wie die des Autors zu den weltwirtschaftlichen Problemen Anfang der 20er Jahre. Unter der aufgeworfenen Fragestellung interessiert in erster Linie André François-Poncets Analyse der (wirtschaftlichen) Lage Deutschlands und seine Vorschläge, sie zu verbessern. Der Autor war, wie so viele Franzosen zu der Zeit, überzeugt, daß »depuis l'armistice, le Reich a pratiqué une politique financière de gaspillage et de luxe effrénées qui devait, sans rémission possible, le mener à l'abîme «" Insofern sei Deutschland bzw. die Reichsregierung - und nicht die ersten Reparationszahlungen - für den finanziellen Zusammenbruch des Reiches verantwortlich: "l'État allemand a lui-même rendu sa déroute financière inévitable, par faiblesse d'abord, par inconscience ensuite, enfin par calcul ${ }^{92}$. Für André François-Poncet war diese Politik eine Fortsetzung des Krieges mit anderen, eben wirtschaftlichen Mitteln ${ }^{93}$. Am finanziellen Zusammenbruch Deutschlands, an den sich daraus ergebenden Zahlungsschwierigkeiten und Wirtschaftsproblemen in ganz Europa gab André François-Poncet allerdings den alliierten Siegern eine Mitschuld: "La grande erreur fut de laisser à ellemême, sans tuteur et sans contrôle, une Allemagne qui était politiquement incapable de marcher, sans s'écarter de sa route, vers le but qui devait être le sien ${ }^{94}$. Die logische Konsequenz aus dem Fehler war, Deutschland unter eine

89 André François-Poncet bedient sich bei dieser Veröffentlichung erstmals des Pseudonyms, das wohl vom lateinischen $»$ Celtae« [Celtae, -arum: die Kelten, die Gallier (im engeren Wortsinn)] herrührt. 1942 veröffentlichte er einige Artikel unter diesem Pseudonym in der Tageszeitung »Le Figaro«, vgl. AN/AP 462, 41 sowie André FRANÇOIS-PONCET, Au fil des jours. Propos d'un libéral, 1942-1962, Paris 1962, S. 1518. Insofern ist die Schrift eindeutig André François-Poncet zuzuordnen, zumal das Typoskript in seinem NachlaB liegt, AN/AP 462, 5. Diese Ansicht bestätigt Renata BoURNAZEL, Rapallo. Ein französisches Trauma, Köln 1976, S. 112, Anm. 93 sowie S. 103-105. Nach ihrer Darstellung sollen André François-Poncet und seine Mitarbeiter sogar die offiziellen Weisungen für die französische Delegation ausgearbeitet haben, ibid. S. 132. Carole Fink behauptet dagegen, daB sich hinter »Celtus« nicht nur André François-Poncet - »from the Economic Section of the MAE« - verbirgt, sondern auch Guillaume de Tarde vom AuBenministerium und Jean Benoist vom Ministerium für öffentliche Arbeiten, vgl. Carole FINK, The Genoa Conference. European Diplomacy 1921-1922, Chapel Hill, London 1984, S. 73, Anm. 15. Abgesehen von der falschen Zuordnung André François-Poncets zum Außenministerium bleibt die Autorin jeden Beleg für ihre Behauptung schuldig.

90 CELTUS [André François-Poncet], La France à Gênes. Un programme français de reconstruction économique de l'Europe, Paris 1922.

91 Ibid. S. 108.

92 Ibid. S. 133.

93 Ibid. S. 142.

94 Ibid. S. 133. 
»contrôle financier«, das heißt eine Haushalts- und Verwaltungsaufsicht der Alliierten, zu stellen, als Voraussetzung für eine internationale Anleihe, die der deutschen Wirtschaft auf die Beine helfen und damit die deutschen Reparationszahlungen wieder fließen lassen sollte. Das war einer der Hauptpunkte seines "programme positif «, das er am Ende des Buches in sieben Punkten zusammenfaßte ${ }^{95}$. Daß die französische Delegation diese Vorstellungen auf der Konferenz von Genua nicht durchsetzen konnte, liegt auch im Wesen solcher Veranstaltungen begründet. Außerdem wurde das Treffen vom englisch-französischen Gegensatz gelähmt und schließlich von der deutsch-russischen Verständigung in Rapallo am 16. April 1922 überschattet, die insbesondere die französische Delegation verschreckte ${ }^{96}$. Mitte Mai gingen die Delegationen auseinander, ohne auch nur eines der anstehenden Probleme gelöst zu haben.

André François-Poncet beschäftigte sich aber weiter mit dem Reparationsproblem. »Le problème des réparations«, schrieb er ein halbes Jahr später im Herbst 1922 in einem Bericht für den Parteitag der Parti républicain démocratique et social, »domine aujourd'hui toute la politique, intérieure et extérieure, de notre pays « ${ }^{97}$. In dem Rapport mit dem Titel »La France et le problème des réparations " stellte er seine Sicht des Hauptproblems der internationalen Beziehungen der 20er Jahre dar, die im einzelnen hier nicht wiederzugeben ist. André François-Poncet kam nach einer detaillierten Wiedergabe der internationalen Reparationsverhandlungen zu dem Schluß, daß »la politique des réparations, telle qu'elle a été pratiquée par les Alliés, a abouti jusqu'ici à un fiasco lamentable $\ll^{98}$. Eine »crise aiguë« treffe Frankreich, ja Europa, obwohl bzw.

96 André François-Poncet schien persönlich verärgert gewesen zu sein, vgl. KESSLER, Tagebücher, S. 309ff.

97 André FRANÇOIS-PONCET, La France et le problème des réparations, Paris 1922, S. 2. Die »Reparationen« stellen einen der kompliziertesten Aspekte der internationalen Politik der Zwischenkriegszeit dar. Eine konzise Einführung in die Gesamtproblematik für die 20er Jahren gibt Peter KRUGER, Deutschland, die Reparationen und das internationale System der 20er Jahre, in: GWU 33 (1982) S. 405-419. Die Meilensteine der Entwicklung sind zuverlässig abzugehen mit Gerd MEYER, Die Reparationspolitik. Ihre auBen- und innenpolitischen Rückwirkungen, in: Karl Dietrich BRACHER, Manfred FUNKE, HansAdolf JACOBSEN (Hg.), Die Weimarer Republik 1918-1933, Bonn ${ }^{3} 1998$, S. 327-342. Die Literatur zur Reparationsproblematik im allgemeinen, wie auch zu speziellen Fragestellungen ist kaum mehr zu überblicken. Siehe die umfassende Bestandsaufnahme und kritische Gesamtdarstellung von Bruce KENT, The Spoils of War. The Politics, Economics, and Diplomacy of Reparations 1918-1932, Oxford 1989.

98 FRANÇOIS-PONCET, Réparations, S. 28. Der Autor gab der französischen (AuBen)Politik, namentlich Briand, der seit Mitte Januar 1921 die Regierung des Bloc national führte und Außenminister war, eine Mitschuld an dem Fiasko: Die Regierung habe auf ein Wunder gehofft und sich hinter dem Versailler Vertrag versteckt. Von Tag zu Tag, von Vorfall zu Vorfall lebend habe sie den Anspruch aufgegeben, die Ereignisse zu steuern. Sie habe zwischen einer nachgiebigen und unnachgiebigen Haltung nie entschieden. Diese 
weil Deutschland drei Jahre nach dem Friedensvertrag von Versailles nicht mehr als 6,519 Mrd. Goldmark bezahlt habe, von denen Frankreich gerade mal 1,937 Mrd. - 447 Millionen in bar - bekommen habe. »Pour en arriver là, l'Allemagne s'y est prise de telle sorte, qu'aujourd'hui sa monnaie est complètement avilie, l'État est sur le rebord de la faillite, et l'Allemagne se déclare de plus incapable de faire aucun paiement avant deux ans ${ }^{99}$. Vor diesem Hintergrund analysierte André François-Poncet die Frankreich offenstehenden Handlungsmöglichkeiten wie den Rückzug aus der Reparationskommission (»C'est retrouver, non pas sa liberté d'action, mais sa liberté d'inaction«), die Feststellung "du manquement volontaire de l'Allemagne « durch die Reparationskommission (»on retombe ainsi dans l'impasse, d'où il s'agit de se tirer«) oder das eigenmächtige Handeln Frankreichs (»Rien, quant à nous, ne nous semblerait plus désastreux «). André François-Poncet forderte demgegenüber einen Eingreifplan: »Il faut que la France ait dans sa main gauche un plan mûri d'action par force, et, dans sa main droite un plan valable d'action par gré « ${ }^{100}$. Mit dieser Doppelstrategie hoffte er, die französischen Ziele erreichen zu können. »La manière douce a plus de chance de réussite si l'on sait qu'à son défaut, la manière forte sera employée. Et la force a d'autant plus d'efficacité qu'elle frappe plus juste et s'exerce à l'endroit le plus sensible «" ${ }^{101}$. André François-Poncet spielte also im Herbst 1922 mit dem Gedanken, die Reparationszahlungen gewaltsam einzutreiben, um die von Deutschland zu zahlenden $50 \mathrm{Mrd}$. Goldmark zu bekommen ${ }^{102}$. Objekt der französischen Begierde war

Ambivalenz, ja Planlosigkeit der französischen Außenpolitik müsse mithilfe eines ausgefeilten Aktionsplanes geändert werden. Da der erst in seinen Einzelheiten ausgearbeitet werden müsse, plädierte André François-Poncet für die Gewährung des von Deutschland geforderten Moratoriums, um Zeit dafür zu gewinnen, vgl. FraNÇOISPONCET, Réparations, S. 31.

99 Die Reichsregierung hatte am 12. Juli 1922 bei der Reparationskommission um einen Zahlungsaufschub gebeten, vgl. MEYER, Reparationspolitik, S. 334. Für 1923 und 1924 seien außerdem keine Barzahlungen möglich, siehe auch Kolb, Weimar, S. 45. Poincaré forderte auf der Konferenz von London vom 7. bis 14. August 1922 von Deutschland "produktive Pfänder« als Gegenleistung für ein Moratorium.

${ }^{100}$ FRANÇOIS-PONCET, Réparations, S. 36. Vgl. auch das Vorwort André François-Poncets zu der Broschüre von Max HosCHILLER, Une enquête en Allemagne, Paris 1922, S. XXI.

101 Ibid.

102 Die Alliierten hatten auf der Konferenz von Paris Ende Januar 1921 eine Reparationsforderung von 269 Mrd. Goldmark erhoben, die Summe hatte der Oberste Rat in Boulogne am 21./22. Juni 1920 vereinbart, siehe MEYER, Reparationspolitik, S. 330. Die Forderung wurde nach Verhandlungen mit Deutschland auf der Londoner Konferenz (März 1921) und der Besetzung von Düsseldorf, Duisburg und Ruhrort durch französische Truppen im sogenannten Londoner Ultimatum (5. Mai 1921) auf $132 \mathrm{Mrd}$. Goldmark reduziert. Die Summe war in zwei Tranchen von 50 bzw. 82 Mrd. zu zahlen. Die 82 Mrd. waren für André François-Poncet nur »un instrument de pression politique«, um die USA und GroBbritannien zu einer Annulierung ihrer Forderungen zu bewegen, vgl. FRANÇOIS-PONCET, Réparations, S. 31. Zum Reparationsproblem im allgemeinen vgl. MOLLER, Europa, S. 45ff., aus deutscher Sicht SCHULZE, Weimar, S. $226 \mathrm{ff}$. 
seit dem Kriegsende das Ruhrgebiet ${ }^{103}$. Ausgangspunkt seiner Überlegungen war eine Analyse der Lage in Deutschland: Das Verschwinden der Monarchie und des preußischen Militarismus habe zum vollständigen Zusammenbruch des Staates geführt. Deutschland leide infolgedessen nicht in erster Linie an einer wirtschaftlichen oder finanziellen, sondern vor allem an einer politischen Krise. Das Reich sei in Auflösung begriffen und drohe, in die Anarchie abzurutschen. Vor diesem Hintergrund müsse der »Erfüllungspolitik « der Regierung Wirth von außen der Rücken gestärkt werden, in dem ihr eine Kontrollkommission zur Seite gestellt wird, die mit einer »force « ausgestattet, diese auch gelegentlich spüren lasse ${ }^{104}$. SchlieBlich habe Deutschland auf »menaces précises « - wie Spa ${ }^{105}$ und London ${ }^{106}$ gezeigt hätten - immer reagiert. André François-Poncet wollte also die mit weitreichenden Kontrollbefugnissen ausgestattete Reparationskommission weiter stärken, indem er sie mit einer

${ }^{103}$ Mit dieser Drohung spielten die Alliierten seit Kriegsende, Poincaré hatte in seiner Barle-Duc-Rede am 24. April 1922 erstmals von einem französischen Alleingang gesprochen. Diese Forderung nach "produktiven Pfändern « erhob er erneut auf der Londoner Reparationskonferenz (7.-14. August 1922), nach dem die Engländer in der Balfour-Note zur Frage der interalliierten Verschuldung und der alliierten Schulden in den USA auf der Rückzahlung ihrer Kredite bestanden hatten. Vor allem die französische Schwerindustrie drängte aus wirtschaftlichen Gründen auf eine langfristige Besetzung des Ruhrgebietes, vgl. z. B. JEANNENEY, Wendel, Bd. I, S. 152f. André François-Poncets Eintreten für eine Besetzung des Ruhrgebietes dürfte auf diesen Einfluß zurückgehen. $\mathrm{Daß}$ François de Wendel seine Prioritäten im Spätsommer 1922 zugunsten des linken Rheinufers veränderte, sei hier nur am Rande erwähnt, vgl. JEANNENEY, Wendel, Bd. I, S. 205. André François-Poncet war inzwischen seinem Einfluß entzogen. Jeanneney bezweifelt übrigens, daß das Comité des forges einen merklichen Einfluß auf die Außenpolitik Poincarés ausgeübt hätte. Zwar konvergierten die politischen Linien François de Wendels und Raymond Poincarés, aber die kurzfristigen Pläne divergierten und der persönliche Einfluß war gering, vgl. JEANNENEY, Wendel, Bd. I, S. 210.

${ }^{104}$ FrançoIS-PONCET, Réparations, S. 33.

${ }^{105}$ Auf der Konferenz von Spa im Juli 1920 stimmte Deutschland - unter ständiger Drohung eines Einmarsches ins Ruhrgebiet - einem Kohleabkommen zu, das die Menge der zu liefernden Kohle von 2,4 auf 2,0 Millionen Tonnen im Monat reduzierte, siehe MEYER, Reparationspolitik, S. 330f.

${ }^{106}$ Die Reichsregierung war am 3. März von der Londoner Gläubigerkonferenz aufgefordert worden, binnen vier Tagen den Pariser Zahlungsplan anzunehmen. Die Forderungen beliefen sich auf $226 \mathrm{Mrd}$. Goldmark, vgl. MEYER, Reparationspolitik, S. 332f. und KOLB, Weimar, S. 44. MOLLER, Europa, S. 45 beziffert die Gesamtforderung auf 269 Mrd. Goldmark. Deutsche Gegenvorschläge wurden als unzureichend abgelehnt und daraufhin am 8. März 1921 Duisburg, Ruhrort und Düsseldorf besetzt. Durch das sogenannte Londoner Ultimatum vom 5. Mai 1921 erzwangen die Ententemächte unter Androhung einer Besetzung des gesamten Ruhrgebietes und einer neuen Blockade die Annahme der inzwischen von der Reparationskommission auf 132 Milliarden Goldmark reduzierten Summe, siehe ibid. Zur Problematik der Zahlen und Zahlenvergleiche bei den Reparationen vgl. Peter KRUGER, Das Reparationsproblem der Weimarer Republik in fragwürdiger Sicht. Kritische Überlegungen zur neuesten Forschung, in: VZG 29 (1981) S. 23-30. 
Exekutivgewalt ausstattete. Das heißt, der Reparationskommission sollte eine polizeiliche, wenn nicht militärische Macht zur Seite gestellt werden. Das käme einer verdeckten Intervention in Deutschland gleich. Seit langem habe Frankreich ein auf das Ruhrgebiet zielendes Sanktionsprogramm, das aber, so scheint er zu bedauern, keine Regierung angewendet habe. André FrançoisPoncet gab zu, daß eine Besetzung des Ruhrgebiets zu einem »certain affolement " in Deutschland führen könne und daß die Aktion Frankreich - bei einseitigem Vorgehen - in offenen Konflikt mit einigen seiner Alliierten bringen könne. »Mais on ne saurait nier que la mesure, en elle même, ne soit une des plus efficaces, une des plus foudroyantes que nous puissions prendre. Ce serait aussi une des plus productives ${ }^{107}$. André François-Poncet glaubte allerdings nicht, daß Frankreich zur Ruhrbesetzung schreiten müsse. Die Inflation mache sich langsam, aber sicher in Deutschland bemerkbar und bringe die Reichsregierung zur Räson. Schließlich sei die Krankheit Deutschlands »plus politique que financière; elle est encore plus financière qu'économique«. Deutschland brauche vor allen Dingen »une monnaie stable, une monnaie saine«. Die notwendige Währungsreform sei eine technische Operation, die erfolgreich durchgeführt werden könne, wenn gleichzeitig der Staatshaushalt ausgeglichen und die Inflation gestoppt werde ${ }^{108}$.

Im Grunde schloß sich André François-Poncet dem Gesundungsplan der Reparationskommission an. Entscheidend aber ist, daß André François-Poncet die schon mit tiefgreifenden Kontrollbefugnissen über Wirtschaft und Staatshaushalt ausgestattete Kommission stärken wollte. Insofern gingen seine deutschlandpolitischen Vorschläge inzwischen weit über die in seinem »programme positif « für die Konferenz von Genua vorgeschlagene Finanzkontrolle Deutschlands hinaus. Überwachung reichte André François-Poncet nicht mehr aus, auf die Durchsetzung der französischen Forderungen kam es ihm inzwischen an. Die wollte er noch mit und nicht gegen Deutschland auf einer "Conférence de détente et d'apaisement « erreichen. Trotz der zahlreichen vorhergehenden und in ihren Ergebnissen von André François-Poncet kritisierten Reparationskonferenzen setzte er sich für die vom französischen Ministerpräsidenten geforderte Konferenz ein.

Si la Conférence dont M. Poincaré a demandé la réunion prochaine évoquait devant elle le problème des réparations dans toute son ampleur, si les Alliés y tombaient d'accord pour approuver le plan d'un système d'ensemble des réparations, comprenant l'entrée en jeu de la compensation des dettes inter-alliées et la réduction correspondante de la dette allemande, la stabilisation du mark et l'application rigoureuse et contrôlée des réformes prévues par le Comité des garanties, si l'Allemagne souscrivait de son plein gré à un tel programme, complété par les prestations en nature et la fourniture de main-d'œuvre, les vœux formulés

${ }^{107}$ FRANÇOIS-PONCET, Réparations, S. 33. Eine zu verstärkende Kontrolle Deutschlands hatte er schon vor der Konferenz von Genua gefordert, s. o. Inzwischen hatte er diese Vorstellungen verschärft.

${ }^{108}$ FRANÇOIS-PONCET, Réparations, S. 34. 
par le Comité des banquiers seraient réalisés; la mobilisation immédiate des bons A et B par voie d'emprunt international des réparations deviendrait possible ${ }^{109}$.

Diese internationale Reparationsanleihe könnte "une ou plusieurs fois" $50 \mathrm{Mrd}$. Goldmark erzielen. Infolgedessen könnte Frankreich beispielsweise über einen Zeitraum von sieben Jahren »une dizaine de milliards de francspapier « erhalten ${ }^{110}$.

Voilà das reparationspolitische Programm André François-Poncets: noch einmal verhandeln, dann aber handeln. Handeln hieß, sich die von Deutschland nicht erbrachten Reparationen mit Gewalt zu holen, sei es durch eine die Reparationskommission unterstützende, nicht näher bestimmte »force«, sei es durch eine militärische Besetzung des Ruhrgebiets. Die auf den ersten Blick den Verhandlungsweg bevorzugende Strategie setzte also letzten Endes auf eine Intervention in Deutschland, um die ausstehenden bzw. immer wieder ins Stocken geratenen Reparationsleistungen für Frankreich einzutreiben. Insofern entwickelte François-Poncets Parteitagsbeitrag die von Ministerpräsident Poincaré Ende 1922 verfolgte Politik ${ }^{111}$. Die Verschärfung seiner reparationspolitischen Gangart reflektiert die Entwicklung der französischen Reparationspolitik nach der gescheiterten Konferenz von Genua, dem Abschluß des deutsch-russischen Vertrages in Rapallo, dem zweiten Moratoriumsgesuch der Reichsregierung und der sogenannten Balfour-Note. Die versiegenden Reparationsleistungen einerseits und die bestehenden angelsächsischen Forderungen an Frankreich andererseits drängten - vor dem Hintergrund der zu erbringenden Aufbauleistungen, Pensionszahlungen u. a. Kriegsfolgelasten - die französische Politik auf den Weg der produktiven Pfänder, einer nichterklärten Fortsetzung des Krieges, die wie eine Flucht nach vorne erscheint.

Angesichts der politischen Übereinstimmung mit Raymond Poincaré ist nicht verwunderlich, daß der französische Ministerpräsident und Außenminister André François-Poncet an die Ruhr schickte, nachdem die französischbelgische Intervention eine miserable Presse in der Welt erhielt. Bei dieser Entscheidung dürfte nicht nur die politische Wegbereitung eine Rolle gespielt haben, sondern auch die ausgezeichneten Deutsch- und Deutschlandkenntnisse sowie die journalistische Erfahrung André François-Poncets. Der Direktor der Société d'Études et d'Informations économiques hatte - wie gesehen Poincaré schon vor und während der Konferenz von Genua gute Dienste geleistet. Also bat der französische Ministerpräsident den ihm politisch Nahestehenden, in Düsseldorf ein zentrales Informationsbüro für die Presse aufzu-

${ }^{109}$ Ibid. S. 35.

${ }^{110} \mathrm{Vgl}$. auch Vorwort in HoSCHILLER, Enquête, S. XX.

${ }^{111}$ Zur französischen Politik vor und während der Ruhrkrise vgl. Jacques BARIÉTY, Die französische Politik in der Ruhrkrise, in: Klaus SchwABE (Hg.), Die Ruhrkrise 1923, Paderborn 1984, S. 11-27 und Denise ARTAUD, Die Hintergründe der Ruhrbesetzung 1923. Das Problem der interalliierten Schulden, in: VZG 27 (1979) S. 241-259. 
bauen $^{112}$. Die $»$ Mission Poncet« hatte drei Aufgaben: Sie sollte erstens den Ministerpräsidenten täglich über die Meinungsbildung in der deutschen Presse und die Stimmung in der Bevölkerung, insbesondere unter den Arbeitern, auf dem laufenden halten, sie sollte zweitens die französischen und internationalen Korrespondenten mit korrekten Informationen versorgen und drittens die deutsche Bevölkerung mit Flugblättern, Broschüren und anderem Propagandamaterial über die französische Politik unterrichten ${ }^{113}$. Für die in dieser Studie aufgeworfenen Fragestellungen sind vor allem die von André FrançoisPoncet verfaßten $\gg$ Note[s] pour la Présidence du Conseil interessant $^{114}$. In den Analysen für den Ministerpräsidenten zog der 36jährige immer wieder Parallelen zum Ersten Weltkrieg: "L'acharnement des Allemands à nous résister est quelque chose de tout à fait extraordinaire. C'est une guerre qui nous est faite, sous une autre forme que la guerre véritable, avec des moyens différents mais tout aussi violente«. Daß er selbst im Herbst 1922 für eine Fortsetzung des Krieges mit anderen Mitteln eingetreten war, erinnerte André François-Poncet in diesem Zusammenhang nicht mehr. Die einzige Lösung sei, "d'étrangler la Ruhr en y produisant un tel chômage, une telle gêne et au besoin une telle famine qu'elle criera au secours et obligera l'Allemagne à céder ${ }^{115}$. Trotz des kriegerischen Charakters der Konfrontation war sich André François-Poncet nach wenigen Tagen an der Ruhr sicher, daß Frankreich als Sieger aus der »guerre économique« hervorgehen werde: »À moins que des effusions de sang ne transforment subitement la situation, nous n'avons qu'à attendre, sans nous troubler, le développement logique des choses et le moment où le fruit enfin mûr tombera dans nos mains ${ }^{116}$. Daß die Ernte so lange auf sich warten ließ, erklärte François-Poncet mit der Politik, in der sich Deutschland - einmal mehr - selbst gefangen habe: „Résister, c'est

${ }^{112}$ Vgl. das Telegramm des AuBenministers an den Kriegsminister vom 21. Januar 1923, in: AMAE, RC, Vol. 275, S. 1. François-Poncet, der drei Mitarbeiter (Max Hoschiller, Paul Leclercq und Raymond Henry) aus der Société d'Études et d'Informations économiques mit an den Rhein brachte, sollte die PR-Maßnahmen der Militäradministration und die des Hochkommissariats koordinieren. Er unterstand dem Befehlshaber der französischen Rheinarmee, General Degoutte. Siehe auch André François-Poncets Schilderung in DERS., Von Versailles nach Potsdam. Frankreich und das deutsche Problem der Gegenwart 1919-1945, Mainz 1949, S. 111f.

${ }^{113}$ Vgl. das Telegramm des AuBenministers an den französischen Konsul in Düsseldorf vom 27. Januar 1923, in: AMAE, RC, Vol. 275, S. 5f. sowie die Note André François-Poncets für die Présidence du Conseil vom 31. Januar 1923, in: ibid. S. 29-31.

${ }^{114}$ Siehe die AMAE, RC, Vols. 275-284: Action de la France dans la Ruhr/Mission de Presse et d'Information de M. François-Poncet.

115 Notizen Seydoux von einem Gespräch mit André François-Poncet, in: AMAE, Papiers Seydoux, Vol. 27, note de Seydoux, le 9 février 1923, zitiert nach Stanislas JEANNESSON, Poincaré, la France et la Ruhr (1922-1924). Histoire d'une occupation, Strasbourg 1998, S. 192.

${ }^{116}$ Note pour la Présidence du Conseil vom 5. Februar 1923, in: AMAE, RC, Vol. 275, S. 145 . 
gagner du temps et le temps apportera peut-être un élément imprévu, un incident, une intervention qui transformeront la face des choses, l'offensive heureuse, le miracle, sur lequel les Allemands ont compté jusqu'à l'automne $1918{ }^{117}$. Wie in der Schlußphase des Ersten Weltkrieges seien solche Hoffnungen auch in der laufenden Auseinandersetzung illusionär, wie er im Hinblick auf die innenpolitischen Entwicklungsmöglichkeiten betont:

Révolte de l'industrie moyenne et du commerce, révolte de la petite bourgeoisie sacrifiée, crise économique profonde, troubles intérieurs allant jusqu'à la guerre civile, débâcle financière, rupture du ressort moral, défections plus ou moins généralisées dans la Ruhr, laquelle de ces éventualités se réalisera, laquelle, en se réalisant, entraînera le fléau de la balance? On ne peut encore le prédire avec certitude. Encore moins peut-on prédire quand [Hervorhebung im Original, cws] se produira l'un ou l'autre de ces evénements décisifs. Mais il paraît fatal qu'il se produise et invraisemblablement que l'Allemagne y échappe, si elle poursuit dans la voie où elle s'est engagée ${ }^{118}$.

Angesichts der absehbaren Entwicklung bliebe Frankreich nicht viel anderes zu tun, als den Druck auf Deutschland aufrechtzuerhalten und abzuwarten ${ }^{119}$.

André François-Poncet wartete nicht mehr lange und kehrte im Juli 1923 aus Deutschland zurück ${ }^{120}$. Er übernahm wieder die Direktion der Société d'Études et d'Informations économiques und verstärkte sein parteipolitisches Engagement: Als Mitglied des Exekutivkomitees formulierte er das Wahlprogramm des Parti républicain démocratique et social und kandidierte bei den Wahlen zur Abgeordnetenkammer im Mai 1924 für die Partei ${ }^{121}$. Trotz des Wahlsieges des cartel des gauches zog der Liberal-Konservative ${ }^{122}$ in das

${ }^{117}$ Ibid. S. 162.

118 Ibid. S. 164f.

${ }^{119}$ Note pour la Présidence du Conseil vom 29. März 1923, in: AMAE, RC, Vol. 277, S. 165.

${ }^{120}$ Vgl. seine Äußerung gegenüber Reichsaußenminister Curtius auf der Fahrt von Paris nach London am 22. Juli 1931, in: ADAP, B, Bd. 18, Nr. 69, S. 129. André FrançoisPoncet erklärte bei dieser Gelegenheit, daB er schon damals die Notwendigkeit der Besserung der deutsch-französischen Beziehungen nicht aus den Augen gelassen habe. Siehe auch AMAE, RC, Vol. 284 und 285, die keine von André François-Poncet gezeichneten Notes pour la Présidence du Conseil enthalten. Die übrigen Mitarbeiter der Mission Poncet waren noch bis Ende des Jahres 1923 an der Ruhr. Anfang 1924 übernahm Paul Valot die Mission de Presse et d'Information des Außenministeriums, vgl. AMAE, RC, Vol. 285, S. 180ff.

${ }^{121}$ André FRANÇOIS-PONCET, La politique générale du Parti républicain démocratique et social, Rapport présenté au Congrès annuel du Parti, Paris o. J. [1924]. Die républicains modérés wurden von Raymond Poincaré, Louis Barthou, André Tardieu und PierreÉtienne Flandin gefördert. Vgl. CosToN, Partis, Joumaux et Hommes Politiques, S. 545.

122 André François-Poncet verstand sich immer als »Liberaler«, vgl. DERS., Républicain moderne, ebenso DERS., Auf dem Weg nach Europa. Politisches Tagebuch 1942 bis 1962, Berlin, Mainz 1964, S. 9-11, sowie S. 89-91 bzw. DERS., Au fil des jours, S. 120 125. Zur kulturellen Begründung seines Liberalismus vgl. DERS., Discours français, S. 83f. Zusammenfassende Darstellungen bei BOCK, Perzeption, S. 589f. bzw. Rapports, S. 131ff. und MESSEMER, François-Poncet, S. $510 \mathrm{f}$. 
Palais Bourbon ein. Dort schloß sich der 37jährige der Fraktion der gauche républicaine démocratique an, die von Pierre-Étienne Flandin angeführt wurde ${ }^{123}$. Als Repräsentant des Comité des forges wurde André FrançoisPoncet von den kommunistischen Abgeordneten empfangen, die ihm vorwarfen, mit Deutschland gemeinsame Sache zu machen: »C'est un associé des Boches! , rief Marcel Cachin, als der neue Abgeordnete zum ersten Mal das Wort ergriff $^{124}$. Die kommunistischen Abgeordneten beschuldigten FrançoisPoncet nicht nur vom deutschen Kapitalismus zu profitieren, sondern auch mit einem deutschen Oberst zusammenzuarbeiten. Tatsächlich saß er seit $1920 \mathrm{im}$ Aufsichtsrat der Dillinger Hüttenwerke AG, in dem wohl auch der in Frage stehende Reserveoffizier einen Sitz hatte ${ }^{125}$. Als Mitglied des Ausschusses für Handel und Industrie machte sich André François-Poncet in der Abgeordnetenkammer schnell einen Namen als Wirtschafts- und Finanzpolitiker, so daB er schon neun Monate nach seinem Einzug ins Parlament im Namen der Opposition die Haushalts-, Finanz- und Wirtschaftspolitik der Regierung Herriot attackieren durfte ${ }^{126}$. Seine Kritik richtete sich nicht nur gegen »une politique intérieure de division et de violence, d'aggravation des charges budgétaires, de menaces à l'égard de l'épargne et du capital« des cartel des gauches, sondern auch gegen ihre »politique extérieure de concessions et d'abandons, sans contre-partie « ${ }^{127}$.

Die gegen die Ruhrpolitik der Regierung Herriot erhobenen Vorwürfe bieten einen grundlegenden Einblick in seine deutschlandpolitischen Vorstellungen in dieser Zeit. Schon Anfang des Jahres 1925 hatte André François-Poncet die Ruhr-Politik der Regierung Herriot angegriffen: »nous vous reprochons d'avoir [...] abandonné cette carte que vos prédécesseurs vous avaient procurée et dont nous ne retrouverons jamais l'analogie, pour vous contenter de promesses qui ne seront, elles, tenues, que si on le veut bien! $\aleph^{128}$. Die Ruhr-

${ }^{123}$ Vgl. Bock, Skizze, S. 383.

${ }^{124}$ Vgl. Joumal officiel 1924, Chambre des deputés, $1^{\text {re }}$ Séance du 10 juillet 1924, S. 2576 f.

${ }^{125}$ Vgl. Archives biographiques françaises, London u. a. o. J. [1988], Bd. II, S. 273 und S. 411 sowie Journal officiel 1925, Chambre des députés, Séance du 9 avril 1925 , S. 2164. Auf Anfrage bestätigte die nach wie vor existierende Aktiengesellschaft der Dillinger Hüttenwerke, daß André François-Poncet vom 7. Juli 1920 bis 5. November 1928 dem Aufsichtsrat der AG angehörte. Eigene Recherchen waren in dem Werksarchiv nicht möglich. François-Poncet bemerkte zu den Vorwürfen, daß er zu den Franzosen gehörte, die »de vieux intérêts de famille au service de l'intérêt national« stellten. Louis Loucheur, ehemaliger Minister für den Wiederaufbau bzw. für die besetzten Gebiete, bestätigte, »c'est sur l'initiative formelle du Gouvernement français, sur mon invitation, comme ministre, que notre collègue a accepté de représenter la France dans les conseils de la Sarre«, vgl. Journal officiel 1925, Chambre des députés, Séance du 9 avril 1925. S. 2164.

126 Journal officiel 1925, Chambre des députés, Séance du 9 avril 1925, S. 2163.

${ }^{127}$ Ibid. S. 2164.

${ }^{128}$ Journal officiel 1925, Chambre des députés, Séance du 28 janvier 1925, S. 353. 
besetzung sei ein Trumpf der französischen Politik gewesen, der gegen die Alliierten wie gegen die Deutschen hätte ausgespielt werden können ${ }^{129}$. Die Regierung Poincaré habe den Dawes-Plan akzeptiert, um zu zeigen, daß man nur vorübergehend in den besetzten Gebieten bleiben wolle. Allerdings habe die militärische Räumung der Ruhr vor der Konferenz von London nicht zur Diskussion gestanden. "L'évacuation militaire de la Ruhr devait se faire graduellement, au fur et à mesure que le plan Dawes [...] verrait se produire son exécution régulière, conformément aux conditions qui y étaient stipulées ${ }^{130}$. So hätte Frankreich ein Mittel zur Sicherung seiner Beachtung und zur Sanktionierung seiner Mißachtung durch Deutschland gehabt. Indem Herriot in London - »sans marchander « - die Räumung der Ruhr, zunächst wirtschaftlich, dann militärisch, zugestanden habe, habe er psychologischen Fehler begangen: "Vous avez fait, en ne marchandant pas, une erreur de psychologie allemande, parce que les Allemands ne comprennent que le marchandage ${ }^{131}$. Daß die französische Regierung nicht zuletzt auf britischen Druck zu einer "Art Kapitulation« gezwungen war, hat André François-Poncet übersehen. London wie auch Washington verlangten nämlich von Paris, nachdem Berlin mit dem Abbruch des passiven Widerstandes in der Reparationsfrage kapituliert hatte, einen Verzicht auf die weitere politische Instrumentalisierung der Frage ${ }^{132}$. Insofern konnte die Regierung Herriot nicht mit Deutschland "kuhhandeln", schon gar nicht allein, wie das der Abgeordnete forderte. Für die hier aufgeworfene Frage nach den deutschlandpolitischen Vorstellungen André François-Poncets ist indes die Bedeutung dieses Begriffs interessant, der - so der Deutschlandexperte - das ganze Wesen der deutschen Politik und Wirtschaft beschreibe. "Quand ils ont vu, contrairement à leur attente, que vous leur donniez bien plus qu'ils n'avaient jamais osé espérer, ils en ont conclu qu'ils n'avaient pas été aussi vaincus dans la Ruhr qu'ils l'imaginaient eux-mêmes « ${ }^{133}$. Der Fehler des Ministerpräsidenten resultiere, so der Abgeordnete, aus einer Fehleinschätzung Deutschlands und der Deutschen.

Le peuple allemand ne vit pas dans le passé, il vit dans le présent et s'attache à préparer l'avenir. Là où il rencontre la force, quand il ne peut pas la briser, il la respecte, il s'y plie. Là où il rencontre la faiblesse, il en profite. Je conclus [...] de parler ferme et haut et de dresser devant l'Allemagne l'obstacle de sa volonté parce que cet obstacle rendra service à la démocratie allemande elle-même ${ }^{134}$.

${ }^{129}$ Vgl. ibid. S. 352. Siehe auch André FrançoIs-PonCET, Psychologie allemande, in: L'Avenir vom 21. Januar 1925.

${ }^{130} \mathrm{Vgl}$. Journal officiel 1925, Chambre des députés, $1^{\text {re }}$ Séance du 28 janvier 1925, S. 353.

${ }^{131} \mathrm{Vgl}$. Journal officiel 1925, Chambre des députés, $1^{\text {re }}$ Séance du 22 janvier 1925, S. 211.

${ }^{132}$ Siehe GramL, Zwischen Stresemann und Hitler, S. 21f.

133 Journal officiel 1925, Chambre des députés, $1^{\text {re }}$ Séance du 22 janvier 1925, S. 211.

${ }^{134}$ Ibid. 
Trotz dieser Einsicht in den deutschen Volkscharakter und den daraus resultierenden deutschlandpolitischen Vorstellungen äußerte André François-Poncet zu der Zeit erstmals öffentlich den Wunsch, eine Annäherung zwischen Deutschland und Frankreich zustande kommen zu sehen.

Depuis les bancs de l'école jusqu'à ceux-ci, je n'ai jamais cessé d'observer attentivement l'Allemagne et de garder le contact avec elle, non pas avec une pensée d'hostilité systématique, mais avec le désir d'y rencontrer, d'y voir naître les phénomènes politiques qui permettraient enfin un jour le rapprochement des deux grands peuples ${ }^{135}$.

Das war ja auch der Grund für die Überarbeitung seines 1911 gehaltenen Vortrages über den militärischen Geist der Deutschen und die daraus hervorgehende Studie »Ce que pense la jeunesse allemande «. Mit Bedauern stellte André François-Poncet seinerzeit fest, daß eine Annäherung zwischen Deutschland und Frankreich auch in Zukunft nicht möglich sein werde. Inzwischen trat André François-Poncet aber öffentlich für eine deutsch-französische Annäherung ein, für die er in erster Linie ökonomische Argumente ins Feld führte ${ }^{136}$. Angesichts dieser Tatsache dürfte der Meinungsumschwung in der Einschätzung der Möglichkeiten bzw. der Wünschbarkeit einer deutsch-französischen Zusammenarbeit auf den Einfluß des französischen Schwerindustriellenverbandes und insbesondere auf den von Robert Pinot zurückzuführen sein. Er war aber auch eine Konsequenz der fehlgeschlagenen Ruhrbesetzung: Wenn Frankreich nicht allein und gegen den Willen seiner Alliierten Deutschland zu einer wirtschaftlichen Zusammenarbeit zwingen kann, dann muß das Land auf andere, kooperative Mittel zurückgreifen, um sein Ziel zu erreichen. Was man ökonomisch für notwendig hält, muß man auch politisch wollen. Diesen Zusammenhang zwischen wirtschaftlicher Zusammenarbeit und politischer Verständigung erkannte André François-Poncet - wie viele seiner Landsleute - erst nach der Ruhrbesetzung. »Ich bin immer schon Befürworter einer französisch-deutschen Annäherung gewesen«, behauptete er 1927 in leichter Übertreibung in einem Beitrag für die Zeitschrift »Die Hilfe ${ }^{137}$. André François-Poncet sah auf einmal nicht nur den Frieden und den Völkerbund in Gefahr, sondern gleich die gesamte abendländische Kultur in ihrer Zukunft bedroht, wenn Frankreich und Deutschland keine Verständigung erzielten. Allerdings müsse man sich mit der französischdeutschen Annäherung Zeit lassen und auf den richtigen Feldern beginnen: »Meines Erachtens muß die Annäherung zuerst auf dem Gebiet der wirtschaftlichen und der intellektuellen tatsächlichen Zustände gesucht werden. Wenn die materiellen und moralischen Interessen miteinander

${ }^{135}$ Ibid.

${ }^{136}$ André FRANÇOIS-PONCET, Die französisch-deutsche Wirtschaftsverständigung, in: Zeitschrift für Politik 15 (1926) S. 514-518.

${ }^{137}$ André FRANÇOIS-PONCET, Wir brauchen Zeit!, in: Die Hilfe. Zeitschrift für Politik, Literatur und Kunst 34 (1927) S. 24. 
verbunden werden, dann kann allmählich eine Atmosphäre entstehen, in der die politischen Schwierigkeiten reguliert werden können ${ }^{138}$. Das sei vielleicht der längste, aber auch der sicherste Weg zur französisch-deutschen Verständigung. Was auch immer die Gründe für seinen Meinungsumschwung in der Einschätzung der deutsch-französischen Beziehungen gewesen sein mögen, Deutschland blieb in der politischen Arbeit André François-Poncets bis zum Ende der 20er bzw. bis zum Anfang der 30er Jahre im Hintergrund. Obwohl in der Zeit nicht nur der Vertrag von Locarno, sondern auch die Schaffung der Internationalen Rohstahlgemeinschaft ${ }^{139}$ den Weg für eine engere Zusammenarbeit zwischen Deutschland und Frankreich zu ebnen schienen, konzentrierte er sich in diesen Jahren auf die französische Innenpolitik: Als der Wirtschafts- und Finanzfachmann der Opposition kritisierte er während der Franc-Krise unter dem cartel des gauches nicht nur die Haushalts-, Finanz- und Wirtschaftspolitik der Mitte-Links-Regierung Herriots, sondern auch die der nachfolgenden Regierungen Painlevé und Briand ${ }^{140}$. Obwohl er in seiner Kritik die deflationistische Wirtschafts- und Finanzpolitik von Poincaré, der am 23. Juli 1926 wieder das Ruder in Frankreich übernahm, vorwegnahm, wurde André François-Poncet nicht in die Regierung der Union nationale aufgenommen ${ }^{141}$. Erst nach deren überwältigendem Erfolg bei den

${ }^{138}$ Ibid.

${ }^{139}$ Zum Hintergrund siehe Jacques BARIETY, Das Zustandekommen der Internationalen Rohstahlgemeinschaft (1926) als Alternative zum mißlungenen "Schwerindustriellen Projekt « des Versailler Vertrages, in: Hans MOMMSEN (Hg.), Industrielles System und politische Entwicklung in der Weimarer Republik, Düsseldorf 1974, S. 552-568. Bariéty sieht in der Entstehung der Internationalen Rohstahlgemeinschaft den Anfang der »Revision des [Versailler] Friedenswerkes«, S. 556. Vgl. auch Ulrich NOCKEN, Das Internationale Stahlkartell und die deutsch-französischen Beziehungen 1924-1932, in: Gustav SCHMIDT (Hg.), Konstellationen internationaler Politik 1924-1932: politische und wirtschaftliche Faktoren in den Beziehungen zwischen Westeuropa und den Vereinigten Staaten, Bochum 1983, S. 165-202. Zusammenfassend siehe Clemens A. WURM (Hg.), Internationale Kartelle und Außenpolitik. Beiträge zur Zwischenkriegszeit, Stuttgart 1989.

${ }^{140} \mathrm{Vgl}$. Journal officel 1925, Chambre des députés, Séance du 9 avril 1925, S. 2162-2165 und Journal officiel 1926, Chambre des députés, Séance du 9 juillet 1926, S. 2843ff.: André François-Poncet plädierte für eine »politique de déflation méthodique«.

${ }^{141}$ Das Verhältnis André François-Poncets zu Raymond Poincaré ist nicht so eng und gut gewesen, wie es nach den offensichtlichen Übereinstimmungen in der zu verfolgenden Politik den Anschein haben könnte. Der Abgeordnete François-Poncet warf dem Ministerpräsidenten vor, »de ne pas soutenir, écouter et aider assez la droite de sa majorité«. Die Antwort Poincarés überraschte den Mehrheitsabgeordneten: "Poincaré«, notierte François de Wendel am 16. November 1926 in sein "Cahier«, »qui est je crois assez en confiance avec François-Poncet dont la famille était plutôt sde gauche‘, s'est laissé aller à une véritable diatribe contre nous, avouant qu'il n'avait jamais pu supporter la majorité du Bloc national, que c'étaient des gens du Seize Mai et qu'ils le dégoûtaient! [...] Nous pensions bien que c'était là son sentiment intime, mais nous n'aurions pas cru qu'il l'avouerait aussi crument«, zitiert nach JEANNENEY, Wendel, Bd. II, S. 511, siehe 
Parlamentswahlen Ende April 1928 - die radicaux schieden aus der Regierung aus - wurde André François-Poncet mehrfach Unterstaatssekretär ${ }^{142}$. Diese Stationen seines politischen Werdegangs brauchen hier nicht im einzelnen beleuchtet werden, weil sie weder einen Bezug zu Deutschland hatten noch die deutschlandbezogenen Vorstellungen André François-Poncets veränderten ${ }^{143}$.

Festzuhalten aber bleibt, daß André François-Poncet in den 20er Jahren die Akzente in seinen deutschlandpolitischen Vorstellungen verschoben hatte. Entsprechend seinem dichotomen Deutschlandbild sah er für die französische Deutschlandpolitik zwei Handlungsmöglichkeiten: Kooperation oder Konfrontation. Wie am Beispiel seiner reparationspolitischen Vorstellungen gezeigt, setzte er nach dem Ersten Weltkrieg auf eine Zusammenarbeit mit Deutschland, indem beide Länder am Verhandlungstisch eine Lösung für die anstehenden Probleme suchen. Ist die von seiner Seite im Prinzip gewünschte Zusammenarbeit, aus welchen Gründen auch immer, nicht möglich, greift André François-Poncet zur alternativen Handlungsmöglichkeit, der Konfrontation. Der Deutschlandpolitiker war im Zweifelsfall immer bereit - und er verlangte dies auch von seinem Land und dessen Außenpolitikern -, politischen und wirtschaftlichen Druck auf Deutschland auszuüben, ja sogar militärische Mittel anzuwenden, um das Reich, wie im Fall der Reparationszahlungen, zur Erfüllung seiner Verpflichtungen zu zwingen. André François-Poncet fällte die Entscheidung zwischen seinen deutschlandpolitischen Handlungsoptionen in Abhängigkeit von der deutschen Politik bzw. seiner Wahrnehmung derselben. Das setzt eine ständige Beobachtung und gegebenenfalls eine zuverlässige Kontrolle des Nachbarlandes voraus, um zu sehen, ob sich Deutschland den französischen Vorstellungen entsprechend

auch Bd. III, S. 1176, Anm. 5: In einem Interview, das der Autor mit François-Poncet am 14. April 1972 führte, konnte er sich an die Episode nicht mehr erinnern, die ihm aber »très vraisemblable« erschien: »Poincaré était, comme moi, un srépublicain<. Mais pas Wendel ....

${ }^{142}$ Zunächst »Sous-secrétaire d'État de l'enseignement technique et des beaux-arts« im (5.) Kabinett Poincaré (11. November 1928-26. Juli 1929), im (1.) Kabinett Tardieu (2. November 1929 bis 17. Februar 1930) als Unterstaatssekretär nur noch für die Schönen Künste zuständig, im 2. Kabinett Tardieu Unterstaatssekretär für Volkswirtschaft (2. März bis 5. Dezember 1930) und schlieBlich im (1.) Kabinett Laval »Sous-secrétaire d'État de la présidence et de l'économie nationale« (21. Januar 1931 bis 12. Januar 1932). André François-Poncet hatte seine Wiederwahl François de Wendel zu verdanken, der einen aussichtsreichen Gegenkandidaten in seinem Wahlkreis zum Verzicht bewog, vgl. JEANNENEY, Wendel, Bd. II, S. 530. André François-Poncet arbeitete um 1928 in der Umgebung Briands, den er mit seinem Rat unterstïtzte, vgl. Ne quid nimis. Remise à $M$. André François-Poncet, Ambassadeur de France, de l'épée d'Académicien qui lui a été offerte à l'occasion de son élection à l'Académie française, le 17 janvier 1953, o. O. und J. [Paris 1953], S. 9.

${ }^{143} \mathrm{Vgl}$. Journal officiel 1929 und die Sammlung seiner Reden vom November 1928 bis Oktober 1929, die er übrigens Raymond Poincaré gewidmet hat: FRANÇOIS-PONCET, Discours français. 
verhält. Ist dies der Fall, steht einer deutsch-französischen Zusammenarbeit nichts im Wege, zumal André François-Poncet die wirtschaftliche Zusammenarbeit der beiden Länder aus ökonomischen Gründen für notwendig erachtete. Entsprach die deutsche Politik nicht den französischen Vorstellungen, dann schreckte André François-Poncet bei aller persönlichen Sympathie für Deutschland und bei aller Einsicht in die wirtschaftliche Notwendigkeit einer deutsch-französischen Zusammenarbeit nicht vor einer Konfrontation mit Deutschland zurïck, wie seine Haltung vor und während der Ruhrbesetzung zeigte. Entsprach die deutsche Politik aber den französischen Vorstellungen, dann war André François-Poncet wieder zu einer Kooperation mit Deutschland bereit. Die konnte er aber Ende der 20er Jahre als Unterstaatssekretär für Kunst kaum vorantreiben. Erst als André François-Poncet im März 1930 Unterstaatssekretär für Volkswirtschaft und im Januar des folgenden Jahres als solcher der Présidence du conseil zugeordnet wurde, rückte er vor dem Hintergrund der Weltwirtschaftskrise wieder ins Zentrum der aktuellen Politik und kam - wie zu zeigen sein wird - wieder stärker mit Deutschland in Kontakt. André François-Poncet versuchte, seine Vorstellung von einer wirtschaftlichen Annäherung, ja deutsch-französischen Zusammenarbeit bei dieser Gelegenheit zu verwirklichen. $\mathrm{Ob}$ er seinen Vorstellungen einen Schritt näher kam, ist im folgenden ebenso darzustellen, wie die Rückwirkungen seiner Bemühungen auf seine deutschlandpolitischen Vorstellungen.

\subsection{Etappen auf dem Weg zur Verständigung}

Frankreich war Ende der 20er bzw. Anfang der 30er Jahre in einer starken Position. Die Auswirkungen der mit dem New Yorker Börsencrash vom 24. Oktober 1929 einsetzenden Weltwirtschaftskrise trafen das Land erst mit zweijähriger Verspätung, als im Herbst 1931 das britische Pfund abgewertet wurde ${ }^{144}$. In der Zwischenzeit konnte Frankreich seine relativ gute, ja im Vergleich zu den schon von der Weltwirtschaftskrise erfaßten Ländern seine sich verbessernde Position zur Erreichung außenpolitischer Ziele nutzen. André François-Poncet spielte bei dem Versuch, Außenpolitik mit wirtschaftlichen und finanziellen Mitteln zu betreiben, eine zentrale Rolle. Als Unterstaatssekretär für Volkswirtschaft war er im Herbst 1930 bei der Tagung des Völkerbundrates in Genf, um mit Vertretern Deutschlands über eine engere Zusam-

144 Zum Hintergrund siehe RÉmOND, Siècle, S. 127ff., aber auch Serge BERSTEIN, Pierre MILZA, Histoire de la France au XX $X^{\mathcal{e}}$ siècle, Bd. II: 1930-1945, Brüssel 1991, S. $17 \mathrm{ff}$. und BORNE, DUBIEF, La crise, $S$. 20ff. 
menarbeit deutsch-französischer Industrien zu verhandeln ${ }^{145}$. Er kam aber bei seinen Gesprächen nicht recht voran, da die deutsch-französischen Beziehungen überraschend mit einem neuen Problem belastet waren: Hinter den diplomatischen Kulissen hatten der deutsche Außenminister Julius Curtius und der österreichische Vizekanzler Schober einen Plan für eine deutsch-österreichische Zollunion ausgearbeitet, der am 21. März 1931 einer konsternierten Weltöffentlichkeit präsentiert wurde ${ }^{146}$. Vor allem Frankreich, aber auch die Tschechoslowakei und die Länder der Kleinen Entente waren entsetzt. »Grande émotion«, notierte André François-Poncet unter dem 24. März in sein Tagebuch: »On dit: c'est l'Anschluss écon.[omique] « ${ }^{147}$. Tatsächlich konnte die handelspolitische Vereinbarung eine wirtschaftliche Dynamik in Gang setzen, die nicht nur - siehe das Beispiel Zollverein - einem politischen Zusammenschluß Bahn brechen könnte, sondern auch die südosteuropäischen Agrarstaaten in ihren Bann ziehen mußte. Beides konnte der französischen

${ }^{145}$ Vgl. die Aufzeichnungen des Reichsaußenministers Curtius über eine Unterredung mit Briand vom 19. September 1930, in: ADAP, B, Bd. 15, Nr. 221, S. 535f.

${ }^{146}$ Vgl. Schulthess' Europäischer Geschichtskalender 1931, S. 88-91. Die österreichische Presse hatte schon am 17. des Monats über entsprechende Pläne berichtet, vgl. ibid. S. 280. Die Veröffentlichung kam der offiziellen Unterrichtung der Nachbarn zuvor, siehe entsprechende Vorbereitungen in ADAP, B, Bd. 17, Nr. 23, S. 67f. und Nr. 25, S. 71-80. Die ältere Forschung interpretierte das Projekt positiv im Sinne der Reichsregierung und vertrat die Meinung, »daß der Zollplan von 1931 eine der letzten großen Möglichkeiten zur Rettung sowohl des ersten demokratischen deutschen Staates wie des Gedankens der internationalen Zusammenarbeit bot und daB sein Scheitern entscheidend dazu beitrug, das Schicksal des Systems von Weimar und der Ideen von Genf endgültig zu besiegeln «, so Oswald HAUSER, Der Plan einer deutsch-österreichischen Zollunion von 1931 und die europäische Föderation, in: HZ 179 (1975) S. 45-92, Zitat S. 45. Wohlwollend auch Karl Dietrich BRACHER, Die Auflösung der Weimarer Republik. Eine Studie zum Problem des Machtverfalls in der Demokratie, Düsseldorf ${ }^{7} 1984$, S. 352ff. Kritischer schon GRAML, Europa, S. 260f. Die neuere Forschung betonte die »politischen Implikationen« des »handelspolitischen Vorstoßes«, der »das Versailler System mit dem Hebel der Wirtschaft ein Stück weiter ins Wanken bringen « muBte, vgl. Gottfried NIEDHART, Internationale Beziehungen 1917-1947, Paderborn 1989, S. 90; schärfer Peter KRUGER, Deutscher Nationalismus und europäische Verständigung: Das Verhältnis Deutschlands zu Frankreich während der Weimarer Republik, in: Francia 11 (1983) S. 509-525: "Dieses brüskierende und alarmierende Unternehmen war der eigentliche Sündenfall der deutschen Außenpolitik nach der Stresemann-Ära«, ibid. S. 525; DERS., Außenpolitik der Weimarer Republik, S. 533: "Dies war wirklich der Sündenfall der deutschen Außenpolitik, eine Herausforderung des europäischen Staatensystems und eine schlecht kalkulierte dazu«. und DERS., Versailles, S. 165: »ein Paukenschlag, der die europäischen Machtverhältnisse in Frage stellte [...] und die Lage in Europa verschärfte Zur Genese des Projektes vgl. Rolf STEININGER, »Der Angelegenheit ein paneuropäisches Mäntelchen umhängen «. Das deutsch-österreichische Zollunionsprojekt von 1931, in: Ungleiche Partner? Österreich und Deutschland in ihrer gegenseitigen Wahrnehmung. Historische Analysen und Vergleiche aus dem 19. und 20. Jahrhundert, hg. von Michael GEHLER u. a., Stuttgart 1996, S. 441-478.

${ }^{147}$ FRANÇOIS-PONCET, Chronique, 24 mars [1931]. 
Regierung nicht recht sein: Unter der Leitung von André François-Poncet arbeitete sie einerseits einen Gegenplan aus ${ }^{148}$, und versuchte andererseits, die Frage vor der nächsten Tagung der Völkerbundsgremien Mitte Mai in bilateralen Gesprächen mit Deutschland zu klären ${ }^{149}$. Zunächst auf Staatssekretärs-, dann auf Ministerebene sollte eine einvernehmliche Lösung des Problems gesucht werden. Anfang Mai skizzierte André François-Poncet dem deutschen Botschafter in Paris, Leopold von Hoesch, in einem zweistündigen Gespräch die französischen Vorstellungen: Frankreich bot gleichsam eine Europäisierung der geplanten deutsch-österreichischen Zollunion an, d. $\mathbf{h}$. da $\mathrm{B}$ bestimmte Industriezweige Absprachen treffen, um anschließend die Schutzzölle für diese Branchen senken zu können. Der französische Vorschlag griff im Kern den Punkt 4 des programme positif auf, das André FrançoisPoncet Anfang der 20er Jahre für die Weltwirtschaftskonferenz in Genua ausgearbeitet hatte. Deutschland sollte während der Kartellierungsgespräche auf die Fortführung des deutsch-österreichischen Projekts verzichten ${ }^{150}$. Wenn Deutschland auf dessen Fortführung beharre, dann, so drohte François-Poncet, müsse Frankreich »eben in Genf mit aller Schärfe den Kampf deutschösterreichisches Projekt« führen ${ }^{151}$. Das war eindeutig. Trotzdem rückte Deutschland nicht von seinem Plan ab, dieser »méthode particulariste, régionale, tout à fait exemptée d'esprit européen ${ }^{152}$, wie André FrançoisPoncet vor der Abgeordnetenkammer erklärte. Den französischen Druck bekam zunächst Österreich zu spüren: Nach dem Zusammenbruch der Österreichischen Creditanstalt rückte Wien langsam, aber sicher von dem deutsch-österreichischen Vorhaben $a^{153}$. Gleichzeitig lancierte Frankreich seinen Gegenplan, der deutlich François-Poncets Handschrift trägt ${ }^{154}$ : Der plan

${ }^{148} \mathrm{Vgl}$. Telegramm Nr. 454 vom 24. April 1931 des deutschen Botschafters in Paris an das Auswärtige Amt, in: ADAP, B, Bd. 17, Nr. 97, S. 258f. Daß André François-Poncet den französischen Gegenplan ausarbeitete, bestätigt auch Franz von PAPEN, Der Wahrheit eine Gasse, München 1952, S. 104.

${ }^{149}$ Vgl. Telegramm Nr. 214 vom 30. April 1931 des ReichsauBenministers an die Botschaft in Paris, in: ADAP, B, Bd. 17, Nr. 102, S. 267.

${ }^{150} \mathrm{Vgl}$. Telegramm Nr. 107 vom 2. Mai 1931 des deutschen Botschafters in Paris an das Auswärtige Amt, in: ADAP, B, Bd. 17, Nr. 107, S. 277-281, vor allem S. 278-280.

151 PAPEN, Wahrheit, S. 104.

${ }^{152}$ André François-Poncet, in: Journal officiel 1931, Chambre des députés, $2^{e}$ Séance du 5 juin 1931, S. 2863.

${ }^{153}$ GRAML, Europa, S. 260f. Vgl. auch STEININGER, Mäntelchen, S. 474ff. Die französische Regierung nutzte die Bankenkrise in Österreich aus, indem sie die Gewährung eines Kredites an Wien von dessen Verzicht auf die Zollunion abhängig machte, vgl. ibid. S. 477.

${ }^{154}$ Text des Plan constructif in: ADAP, B, Bd. 17, Nr. 126, S. 318f. Zur diplomatischen Vorbereitung siehe auch Telegramm Nr. 120 vom 7. Mai 1931 des Reichsaußenministers an die Botschaft in Rom, in: ADAP, B, Bd. 17, Nr. 117, S. 301f. Andre François-Poncet soll den Plan angeblich am Quai d'Orsay im Büro Aristide Briands entworfen haben, vgl. Jacques BARIÉTY, Der Tardieu-Plan zur Sanierung des Donauraumes (Februar-Mai 
constructif sah namentlich die von ihm seit Anfang der 20er Jahre vorgeschlagenen internationalen Kartelle für bestimmte Produkte vor ${ }^{155}$ sowie ein Zollpräferenzsystem für Österreich (Industriegüter) und die Staaten Mittelund Südosteuropas (landwirtschaftliche Produkte, vor allem Getreide) ${ }^{156}$. Angesichts der unnachgiebigen Haltung Deutschlands mußte sich doch der Völkerbundsrat mit dem Zollunionsprojekt beschäftigen ${ }^{157}$. Der Rat überwies das Projekt auf britischen Vorschlag an den Internationalen Gerichtshof in Den Haag: »Schober accepte«, notierte André François-Poncet unter dem 18. Mai in sein Tagebuch, »et s'engage à ne rien entreprendre avant la décision du conseil. Briand l'en félicite. Grandi parle contre l'accord. Curtius se rallie à Schober ${ }^{158}$. Damit lag das Projekt zumindest bis zur Entscheidung des Den Haager Gerichtshofes auf Eis. In der Zwischenzeit konnte Frankreich dank seiner besseren Wirtschaftslage seine Finanzkraft ausspielen und finanziellen Druck sowohl auf Österreich als auch auf Deutschland ausüben und die südosteuropäischen Agrarstaaten mit finanziellen Versprechungen bei der Stange halten. Die sich verschärfende Wirtschaftskrise in Deutschland und Österreich tat ein übriges, so daß die beiden Länder Anfang September auf einer Tagung des Europa-Ausschusses in Genf ihren Verzicht auf das Zollunionsprojekt erklärten ${ }^{159}$. Zwei Tage später entschied der Internationale

1932), in: BECKER, HILDEBRAND (Hg.), Internationale Beziehungen, S. 361-387, hier S. 368. Ende des Jahres äußerte André François-Poncet als Botschafter in Berlin in einem Gespräch mit dem Chefredakteur der Königsberger Allgemeinen Zeitung sein Bedauern über das Scheitern seines Planes: "Er [André François-Poncet] habe sich in Genf vergeblich bemüht, ein große, wirtschaftliche, internationale Zusammenarbeit einzuleiten; leider habe er - hierbei wurde der Botschafter fast ärgerlich - kein Verständnis gefunden. (Anspielung auf Deutschland.) Man habe seine Vorschläge genommen und zerpfluickt«, vgl. die Niederschrift über die Unterredung mit dem französischen Botschafter FrançoisPoncet am 18.12.31, in: ADAP, B, Bd. XIX, Nr. 135, S. 294-296, hier S. 295.

${ }^{155}$ Ziel war eine "concurrence régularisée«, um zu einer Stabilisierung oder Senkung der Zölle zu kommen. "Nous ne préconisons pas précisément des cartels; mais plutôt des ententes, et, mieux encore, l'entente, l'entente sous les formes multiples qu'elle est capable de prendre selon les problèmes et selon l'ingéniosité des hommes qui l'organisent non pas sur l'ordre et selon les plans théoriques élaborés par des gouvernements tout puissants, mais avec la collaboration et le conseil de ces gouvernements, avec l'aide et le secours des moyens de travails et des expériences préparées par les organismes économiques de Genève«, vgl. Journal officiel 1931, Chambre des députés, $2^{\mathrm{e}}$ Séance du 5 juin 1931, S. 2863.

${ }^{156}$ Ibid. S. 2861-2865.

${ }^{157}$ Vgl. Schulthess' Europäischer Geschichtskalender 1931, S. 538ff.

${ }^{158}$ FRANÇOIS-PONCET, Chronique, 18 mai [1931].

${ }^{159}$ Schulthess' Europäischer Geschichtskalender 1931, S. 573-575. Die Diplomaten beider Länder bereiteten seit Mitte August eine entsprechende Erklärung vor, siehe ADAP, B, Bd. 18, Nr. 141, S. 282-285. In Genf versuchte dann die französische Delegation Einfluß auf die Erklärung zu nehmen, siehe ADAP, B, Bd. 18, Nr.167, S. 362-366 und Nr. 169, S. 367-375. André François-Poncet notierte unter dem 2. September 1931 in sein Tagebuch: »À Genève, l'Aut.[riche] (Schober) et l'All.[emagne] préparent une 
Gerichtshof, daß die Zollunion mit den Österreich betreffenden Bestimmungen des Artikel 88 des Vertrages von St. Germain und den österreichischen Verpflichtungen aus dem Genfer Protokoll vom Oktober 1922 nicht $z$ u vereinbaren $\operatorname{sei}^{160}$.

»L'Allemagne mécontente de son échec«, notierte André François-Poncet am 24. Mai in sein Tagebuch, »il faut faire q[uel]q[ue] chose pour elle ${ }^{161}$. Tatsächlich hatte das Deutsche Reich Hilfe nötig. Seit dem Frühjahr 1931 war Deutschland in einer desolaten Wirtschafts- und Finanzlage, die österreichische Bankenkrise steckte langsam aber sicher das europäische Banken- und Kreditsystem an. Mit der »Notverordnung zur Sicherung von Wirtschaft und Finanzen« vom 5. Juni 1931 versuchte die Reichsregierung der Krise Herr zu werden ${ }^{162}$. Unterdessen klagte sie auf einer Konferenz mit der britischen Regierung in Chequers ihr Leid und forderte freie Hand für ein Moratorium der Reparationszahlungen und daß »am 1 . November spätestens Erleichterungen eintreten müßten ${ }^{163}$. Unter britischem Einfluß schlug der amerikanische Präsident Hoover am 20. Juni 1931 ein Zahlungsmoratorium für ein Jahr vor, das Frankreich zwar nicht gefiel, aber auch nicht verhindern konnte: Das Hoover-Moratorium trat - nach komplizierten Verhandlungen zwischen Frankreich und den Vereinigten Staaten - am 6. Juli 1931 für ein Jahr in $\mathrm{Kraft}^{164}$. Trotz des Zahlungsaufschubs weitete sich die Wirtschaftskrise in Deutschland zu einer Bankenkrise aus: Am 13. Juli mußte die Darmstädter und Nationalbank, eine der vier größten Banken im Reich, ihre Schalter

décl.[aration] de désistement de leur projet. Je suis consulté sur le contenu de cette décl.[aration]«, FRANÇOIS-PONCET, Chronique, 3 septembre [1931].

${ }^{160}$ Schulthess' Europäischer Geschichtskalender 1931, S. 563-565. Zum Hintergrund siehe GRAML, Europa, S. 260f.

${ }^{161}$ FRANÇOIS-PONCET, Chronique, 24 mai [1931] und weiter: »Un emprunt de 100 millions $£$ à quoi bon? Le chômage augmente. Brüning laisse prévoir des nouvelles ordonnances de déflation. Dénoncera-t-on le plan Young? Tout cela devra être évoqué à Londres«. Philipp HEYDE, Das Ende der Reparationen. Deutschland, Frankreich und der YoungPlan, Paderborn 1998 argumentiert S. 160ff., daB Frankreich unter der Leitung Pierre Lavals und André François-Poncets eine »Politik der finanziellen Stärke« gegenüber Deutschland einleitete. Das war m. E. aber nur die eine Seite der französischen Deutschlandpolitik.

${ }^{162}$ Vgl. Schulthess' Europäischer Geschichtskalender 1931, S. 120-132. GRAML, Europa, S. 250ff. vertritt die These, daß die Reichsregierung die Dinge bewußt auf die Spitze getrieben habe, um durch einen zumindest scheinbaren Kollaps der deutschen Finanzen eine Rettungsaktion der Gläubiger Deutschlands zu erzwingen.

${ }^{163} \mathrm{Zu}$ den deutsch-britischen Verhandlungen in Chequers vgl. ADAP, B, Bd. 17, Nr. 169172, S. 402-409, zur Reparationsfrage insbesondere Nr. 172, S. 408f. (Zitat ibid.), siehe auch Schulthess' Europäischer Geschichtskalender 1931, S. 328-331.

164 Text des Hoover-Vorschlages, in: Johannes HoHLFELD (Hg.), Dokumente der Deutschen Politik und Geschichte von 1848 bis zur Gegenwart, Bd. III: Weimarer Republik, 1918 1933, Berlin 1951, S. 348, Dok. 98, siehe auch Schulthess' Europäischer Geschichtskalender 1931, S. 490ff. 
schließen. Der Zusammenbruch der Danat-Bank gefährdete weitere Großbanken, so daß die Reichsregierung zunächst einen "Bankfeiertag " ausrief und die Geldinstitute durch eine staatliche Beteiligung zu sanieren versuchte ${ }^{165}$. Unterdessen hatte Reichskanzler Brüning in einer Radioansprache am 23. Juni eine »offene Aussprache « zwischen Deutschland und Frankreich angeregt, um den "Weg freizumachen für eine großzügige praktische Zusammenarbeit der beiden Länder ${ }^{166}$. Die französische Regierung ging auf den Vorschlag eines "französischen Chequers« ein. Der deutsche Botschafter berichtete am nächsten Tag von einem Gespräch mit Briand: »Französische Regierung sei entschlossen Besuchsidee sofort praktisch anzugreifen und beabsichtigte, alsbald offizielle Einladung an deutsche Minister zu richten, wenn ihr Gewißheit gegeben werde, daß Einladung angenommen werde ${ }^{167}$. André FrançoisPoncet bereitete dann am 25 . Juni in einem vertraulichen Gespräch mit Clemens Lammers ${ }^{168}$ die ganze Palette deutsch-französischer Verhandlungsgegenstände aus, die bei einem Treffen Brüning-Laval ${ }^{169}$ diskutiert werden könnten: "Beseitigung aller großen Hindernisse und Eröffnung positiver Möglichkeiten zur aktiven Kooperation. Reparationsfrage, Ostfrage (Korridor, Polen), usw., andererseits gemeinsame Erschließung von Märkten durch finanzielles und industrielles Zusammenwirken (Plan Flandin) ${ }^{170}$. Das Gesprächsangebot klang insbesondere in der "Ostfrage" verlockend. André François-Poncet glaubte zwar nicht, daß es ohne weiteres möglich sein werde, Deutschland den Korridor und andere Gebiete zurückzugeben. "Dagegen sollten uns die Möglichkeiten ungehinderten Verkehrs mit unserem Osten eröffnet werden. Der Weg könne über eine tiefere Verständigung mit Polen zwecks wirtschaftlicher Kooperation gewonnen werden. Das sei vor allem möglich, wenn eine wirkliche Bereinigung unseres Verhältnisses zu Frank-

${ }^{165}$ Siehe GRAML, Europa, S. 255.

${ }^{166}$ Text der Rede vom 23. Juni in: Schluthess' Europäischer Geschichtskalender 1931, S. 145-148, vor allem S. 146.

${ }^{167}$ Telegramm Nr. 675 des deutschen Botschafters in Paris an das Auswärtige Amt vom 24. Juni 1931, in: ADAP, B, Bd. 17, Nr. 203, S. 483-486, hier S. 483. Von Hoesch bestätigte zwar die grundsätzliche Bereitwilligkeit des Reichskanzlers, schränkte aber ein, daß ein Besuch nicht vor der Regelung des Hoover-Vorschlages möglich sei, weil die kritische Lage in Deutschland die Anwesenheit der Minister erfordere.

${ }^{168}$ Aufsichtsratsmitglied der Bank für deutsche Industrie-Obligationen und deutscher Delegierter in der Zehner-Kommission des Europa-Ausschusses.

169 Pierre Laval war in den 30er Jahren mehrfach französischer Ministerpräsident und Außenminister. Seiner »politique mouvante zwischen Deutschland, Italien und der Sowjetunion blieb ein Erfolg verwehrt. Nach der französischen Niederlage Kollaborateur der ersten Stunde ging er mit dem Vichy-Regime unter, siehe zu seiner Außenpolitik Fred KUPFERMAN, Pierre Laval diplomate, in: Politique Étrangère 51 (1986) S. 57-66 und zu seinem Leben DERS., Pierre Laval (1883-1945), Paris 1987 zuletzt Jean-Paul COINTET, Pierre Laval, Paris 1993.

${ }^{170}$ Schreiben Clemens Lammers an Reichskanzler Brüning vom 25. Juni 1931, in: ADAP, B, Bd. 17, Nr. 207, S. 494f. 
reich erfolge ${ }^{171}$. Zwei Tage später drängte Ministerpräsident Laval aus innenpolitischen Gründen beim deutschen Botschafter in Paris auf eine schnelle Aussprache mit der Reichsregierung, die einem Spitzentreffen aber erst nach dem Abschluß der interalliierten Verhandlungen über den HooverVorschlag zustimmen wollte ${ }^{172}$. Das war Anfang Juli der Fall, so daß ein Termin gesucht werden konnte. Zunächst war Ende Juli für das deutsch-französische Regierungstreffen im Gespräch, dann sollten sich der Reichskanzler und der Ministerpräsident vor der nach London einberufenen 7-Mächte-Konferenz in Paris treffen ${ }^{173}$. Zuvor trafen sich jedoch eine britische und eine amerikanische Delegation (u. a. der britische Außenminister Henderson und der Botschafter Tyrell sowie der US-Außenminister Stimson und der Botschafter Edge) am 16. Juli mit der französischen Regierung (u. a. Ministerpräsident Laval, Außenminister Briand und Finanzminister Flandin) in Paris, um über die »crise allemande « zu beraten ${ }^{174}$. Einen Tag später ließ Laval den Ministerrat ein "projet français « absegnen, das einen 500-Millionen-DollarKredit der französischen, britischen und amerikanischen Notenbanken für die Reichsbank vorsah ${ }^{175}$. Im Gegenzug sollte Deutschland nicht nur materielle, sondern auch politische Sicherheiten geben: Eine »trève polit.[ique] de 10 ans « sollte geschlossen werden, die u. a. die Respektierung des Status quo, den Verzicht auf den Anschluß und den Bau des Panzerkreuzers B vorsah ${ }^{176}$. "[U]n second Versailles«, notierte André François-Poncet an den Rand seines Tagebuches, in dem er die Forderungen als unannehmbar qualifizierte: »évid.[emment] impossible à accepter pour un gouv.[ernement] accusé de capituler devant l'étrang.[er] par une oppos.[ition] nat.[ionaliste] de plus en plus forte ${ }^{177}$. Daß darüber hinaus die Reichsregierung die französischen Anleiheangebote ablehnte, weil die Anleihen die anvisierte Aushebelung des Young-Planes erschweren werde, scheint André François-Poncet nicht erkannt

171 Ibid.

${ }^{172}$ Vgl. Telegramm Nr. 686 vom 27. Juni des deutschen Botschafters in Paris an das Auswärtige Amt, in: ADAP, B, Bd. 17, Nr. 212, S. 502.

${ }^{173}$ Vgl. Telegramm Nr. 737 vom 8. Juli des deutschen Botschafters an das Auswärtige Amt, in: ADAP, B, Bd. 18, Nr. 16, S. $32 f$.

${ }^{174}$ Vgl. FRANÇOIS-PONCET, Chronique, 16 juillet [1931]. Als Unterstaatssekretär für Volkswirtschaft nahm André François-Poncet an der Konferenz teil, ibid. Siehe auch Schulthess' Europäischer Geschichtskalender 1931, S. 501. Demnach habe die britische Regierung eine Konferenz der interessierten Mächte für den 20. Juli in London vorgeschlagen. Darauf lud die französische Regierung den deutschen Reichskanzler und den deutschen Außenminister nach Paris ein.

${ }^{175}$ Vgl. FRANÇOIS-PONCET, Chronique, 17 juillet [1931] und DERS., Souvenirs, S. 22. Der Gedanke, kurzfristige Kredite aus Frankreich in langfristige umzuwandeln, war schon im Sommer 1930 entwickelt worden und schnell mit politischen Forderungen verbunden worden, vgl. GRAML, Zwischen Stresemann und Hitler, S. 81ff.

${ }^{176}$ FRANÇOIS-PONCET, Chronique, 17 juillet [1931].

${ }^{177}$ Ibid. Diese Bewertung findet sich natürlich nicht in seinen veröffentlichten Erinnerungen. 
zu haben ${ }^{178}$. Wie von ihm erwartet, lehnten die deutschen Besucher unter der Führung des Reichskanzlers Brüning den Deal »Geld gegen Garantien« bei den deutsch-französischen Gesprächen in Paris ab: »on n'aboutit pas «, notierte André François-Poncet unter dem 19. Juli in sein Tagebuch, »Br.[üning] ne veut pas s'engager ${ }^{179}$. Mit dieser Weigerung war der $»$ Gedanke eines politischen Moratoriums « aber nicht vom Tisch. Der britische Außenminister Henderson wollte ihn - allerdings um die Hälfte der Laufzeit auf fünf Jahre reduziert - zwei Tage später auf der Londoner Konferenz erneut ins Gespräch bringen, konnte aber von Reichsaußenminister Curtius von dem Vorhaben abgebracht werden. Curtius konnte Henderson bis zur Klärung der finanziellen Fragen hinhalten und ihn mit Hinweis auf »so etwas wie ein pacte consultatif» ablenken ${ }^{180}$. Infolgedessen diskutierten die Delegationen auf der Londoner Konferenz in erster Linie Möglichkeiten, die finanzielle Lage des Reiches zu verbessern ${ }^{181}$. Sie vereinbarten, den Notenbankchefs ihrer Länder vorzuschlagen, den 100-Millionen-Dollar Kredit für die Reichsbank bei Ablauf um drei Monate zu verlängern. Außerdem empfahlen sie der BIZ, ein Komitee einzusetzen, das den unmittelbaren Bedarf neuer Kredite Deutschlands prüfen, sowie die Möglichkeit der Umwandlung eines Teiles der kurzfristigen Kredite in langfristige untersuchen sollte. Die Konferenz beschloß auch, ein Expertenkomitee mit der Ausarbeitung der Details des Zahlungsmoratoriums zu beauftragen $^{182}$.

Aufgrund der bescheidenen Ergebnisse der deutsch-französischen Aussprache in Paris fühlte sich André François-Poncet bemüßigt, auf der gemeinsamen Fahrt nach London Reichsaußenminister Curtius in einem Gespräch unter vier Augen weitergehende Angebote zu unterbreiten: Der Unterstaatssekretär

${ }^{178}$ GRAML, Zwischen Stresemann und Hitler, S. 151ff.

${ }^{179}$ FrANÇOIS-PONCET, Chronique, 18 juillet [1931]. In einem Kommuniqué ließen die Regierungen nach den Besprechungen verlauten, daß die französische Regierung »unter Vorbehalt gewisser finanzieller Garantien und Maßnahmen der politischen Beruhigung (Mesures d'apaisement politique) bereit sind, die Modalitäten einer finanziellen Zusammenarbeit im internationalen Rahmen später zu diskutieren«, siehe Schulthess' Europäischer Geschichtskalender 1931, S. 375f., Zitat S. 376. "Le communiqué est creux «, notierte André François-Poncet in sein Tagebuch. Zu den deutsch-französischen Gesprächen siehe auch »Aufzeichnungen über den Verlauf und Ergebnis der deutschfranzösischen und der internationalen Besprechungen in Paris vom 18. und 19. Juli«, in: ADAP, B, Bd. 18, Nr. 67, S. 115-126 und die mit den oben gemachten Vorbehalten zu sehende Schilderung Heinrich Brünings, in: DERS., Memoiren 1918-1934, Stuttgart 1970, S. 345-355.

${ }^{180}$ Vgl. Aufzeichnung des Reichsministers des Auswärtigen Curtius (z. Z. London) vom 22. Juli 1931, in: ADAP, B, Bd. 18, Nr. 68, S. 126-128.

${ }^{181}$ Vgl. Schulthess' Europäischer Geschichtskalender 1931, S. 501-506. Siehe auch die mit den oben gemachten Vorbehalten zu sehende Schilderung Brünings, in DERS., Memoiren, S. 355-362.

${ }^{182}$ Zum Ergebnis der Londoner Sachverständigenkonferenz vgl. Schulthess' Europäischer Geschichtskalender 1931, S. 506f. 
stellte nicht nur eine "koloniale Betätigung " in Aussicht, sondern auch ein Gespräch mit Polen über die Möglichkeiten einer »Revision« der deutschpolnischen Grenze. Außerdem sagte er dem Reichsaußenminister »sehr offenherzig ", wie der meinte, daß Deutschland nicht auf eine Anleihe hinsteuern dürfe: "Die politischen Schwierigkeiten, die damit verbunden wären, ließen sich im Augenblick nicht überwinden«. Deutschland müsse zunächst mit »kleineren Maßnahmen auskommen. Vielleicht werde in einigen Wochen oder Monaten eine völlig andere Lage geschaffen«. Der französische Ministerpräsident bereite seine Öffentlichkeit »immer stärker« auf »deutsch-französische Verständigungsverhandlungen« und die »Notwendigkeit weitgehender Rücksichtnahme auf deutsche Lage" vor. "Die Anleihefrage gewinne daher ein ganz anderes Gesicht, wenn wir sie nach einigen Monaten noch anschneiden müßten ${ }^{183}$. Mit den Aussagen seines Unterstaatssekretärs konfrontiert, bemerkte Ministerpräsident Laval in einem Gespräch mit Reichskanzler Brüning und Außenminister Curtius auf der Rückfahrt von London nicht zu unrecht, $\mathrm{da} ß$ sich André François-Poncets Einstellung zwar im allgemeinen mit seiner decke, "Poncet ginge ihm aber in seinen Plänen zu weit ${ }^{184}$. Laval rühmte dessen Arbeitskraft, lebendigen Geist und große wirtschaftliche Erfahrung, sparte aber auch nicht an Kritik: »So meinte er $u$. a., daß sein reicher Geist [André François-Poncets, cws] ein wenig verwirrt wäre, gewissermaßen mit Ideen wuchere ${ }^{185}$. Trotz der Einschränkung hatten die Vorstellungen Gewicht. Denn André François-Poncet war seit Anfang Juli als zukünftiger Botschafter Frankreichs in Berlin im Gespräch. Ministerpräsident Laval bestätigte Brüning und Curtius, daß Poncet den Botschafterposten in Berlin persönlich wünsche, schränkte aber ein, daB die Berufung Poncets noch keineswegs beschlossene Sache $\operatorname{sei}^{186}$. Der Wunsch des 44 jährigen zeigt, daß

${ }^{183}$ Vgl. Aufzeichnung des Reichsministers des Auswärtigen Curtius (z. Z. London) vom 22. Juli 1931, in: ADAP, B, Bd. 18, Nr. 69, S. 128-130.

${ }^{184}$ Vgl. Aufzeichnung des Reichsministers des Auswärtigen Curtius vom 25. Juli 1931, in: ADAP, B, Bd. 18, Nr. 77, S. 147-150, hier S. 147.

${ }^{185}$ Ibid.

${ }^{186}$ Ibid. Reichskanzler Brüning erklärte übrigens nach dieser Aufzeichnung gegenüber dem Ministerpräsidenten sein »prinzipielles Einverständnis « mit der Wahl, schränkte aber ein, daß man sich erst mit dem Reichspräsidenten ins Benehmen setzen müBte. In seinen Erinnerungen machte Brüning nachträglich Bedenken gegen André François-Poncet geitend, vgl. BRUNING, Memoiren, S. 361: "Bei aller Anerkennung der großen Fähigkeiten François-Poncets hatte ich doch instinktiv das Gefühl, er sei nicht der geeignete Mann. Ich versuchte vorsichtig, Margerie noch zu halten, indem ich Laval sagte, daB wir naturlich gegen die Wünsche der französischen Regierung keinerlei Bedenken hätten. Auf der andern Seite lege ich aber Wert darauf festzustellen, daB eine Abberufung Margeries in keiner Weise von der deutschen Regierung gewünscht würde. Vielleicht würde in einem Zeitalter, in dem wie ich erhoffe, menschliche Beziehungen zwischen den verantwortlichen Politikern die Regeln sein würden, es an sich gut sein, wenn der normale Verkehr durch die Diplomaten der alten Schule liefe, sollte das nicht seine Ansicht sein, so würde ich niemanden lieber in Berlin begrüBen als François-Poncet«. 
ihm die deutsch-französische Annäherung am Herzen lag und daß er - trotz aller Rückschläge - nach wie vor an eine deutsch-französische Verständigung glaubte. Die wollte André François-Poncet - wie gesehen - mit weitreichenden Zugeständnissen erreichen. Der Botschafter in spe stellte schon am 9. Juli in einem ausführlichen Gespräch mit Leo Simon, deutscher Industrieller und Mitglied der Deutsch-Französischen Gesellschaft, grundsätzlich eine Revision des Versailler Vertrages in Aussicht: »Man sei sich auch hier darüber klar, daß der Vertrag von Versailles ein Menschenwerk sei und somit nicht von Ewigkeitsdauer, seine radikale Änderung unter weitgehender Berücksichtigung der deutschen Ziele sei aber das Ende einer Entwicklung, an deren Anfang die Wiederherstellung vertrauensvollerer Beziehungen stehen

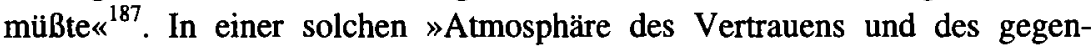
seitigen guten Willens« könne zunächst die Lösung der Saarfrage in Angriff genommen werden ${ }^{188}$. Anschließend könne, so der designierte Botschafter, die Gewährung längerfristiger Kredite in Betracht gezogen werden; auch eine freundschaftliche Vermittlung Frankreichs zugunsten Deutschlands Polen gegenüber liege im Bereich des Möglichen, nachdem vorher zwischen Deutschland und Polen in geeigneter Weise »eine Art Gottesfrieden« hergestellt worden sei. Dies seien die Etappen auf dem Weg einer Verständigung »größten Stiles«, die André François-Poncet als »Endziel zwischen den beiden Ländern« anstrebte. Die sei aber nur mit Geduld und Konsequenz durch eine geradlinige Politik Deutschlands Frankreich gegenüber zu erreichen. "Für eine derartige Politik werde er eventuell als Botschafter Frankreichs sich einsetzen, wenn er die Gewißheit hätte, die volle Unterstützung des Herrn Reichskanzlers zu haben und ihm die Möglichkeit gegeben wäre, sich stets rückhaltlos und frei von diplomatisch-bürokratischem

Laut André François-Poncets Tagebuch hat das Reich am 10. August seiner Nominierung zugestimmt, vgl. FrançOIS-PONCET, Chronique, 10 août [1931]. Der in Berlin amtierende Botschafter, Margerie, bat einige Tage später Ministerpräsident Laval, seine Ablösung nicht zu überstürzen und ihn - und nicht André François-Poncet - mit der Betreuung der französischen Minister in Berlin zu beauftragen, so daß André FrançoisPoncet von dem geplanten Besuch ausgeschaltet bleiben werde, wie der deutsche Botschafter in Paris in einem Telegramm an das Auswärtige Amt am 13. August 1931 berichtete, in: ADAP, B, Nr. 134, S. 266-269, hier S. 267. Trotz der Bitte Margeries nominierte eine Woche später der französische Ministerrat André François-Poncet zum Botschafter in Berlin, vgl. FRANÇOIS-PONCET, Chronique, 20 août [1931] und Schulthess' Europäischer Geschichtskalender 1931, S. 377.

${ }^{187}$ Leo Simon informierte in einem auf den 9. Juli datierten Schreiben Reichsinnenminister Wirth, der das Schreiben an den Reichskanzler Brüning weiterleiten sollte, vgl. ADAP, B, Bd. 18, Nr. 22, S. 41-44, hier S. 41.

${ }^{188}$ Er schlug eine Ablösung der Minen gegen 200-300 Millionen Goldmark und/oder die Herstellung eines Regimes vor, welches auf die wirtschaftlichen Bedürfnisse Rücksicht nähme, die im Laufe der letzten 10-12 Jahre aus dem gegenwärtigen Status erwachsen seien. 
Formelkram mit ihm aussprechen zu können«. Aufgrund der Haltung der deutschen Presse seien ihm, François-Poncet, inzwischen aber Zweifel gekommen, »ob er das sich gesteckte Ziel, als Botschafter Frankreichs der peace-maker zwischen unsern beiden Ländern zu werden erreichen könne«. Leo Simon hielt den designierten Botschafter für »den geeignetsten Exponenten einer solchen Politik Frankreichs « und für den »aufrichtigste[n] Vertreter einer deutsch-französischen Verständigung «. Diese Begeisterung über die Nominierung François-Poncets mochte der deutsche Botschafter in Paris, der ein »geradzu leidenschaftlicher Verfechter nicht nur einer deutsch-französischen Annäherung, sondern einer dauerhaften Verständigung « gewesen sein soll, nicht uneingeschränkt teilen ${ }^{189}$. Nach der Einschätzung von Hoesch bewege sich der künftige Kollege nicht aus dem »Rahmen des normalen Denkens eines französischen Politikers der rechten Mitte « hinaus. Hin- und hergerissen zwischen seiner "zweifellos nationalistischen Grundeinstellung " und seiner »inneren Zuneigung « zu Deutschland habe er noch keine klare Linie gefunden. Je nachdem, welche Seite unter dem aktuellen Eindruck in Berlin die Oberhand gewinnen würde, werde sich sein Wirken in Deutschland gestalten. Wenn die französische Regierung sich entschließe, François-Poncet nach Berlin zu schicken, so bedeute dies zweifellos die Bekundung des Wunsches nach einer aktiven, auf Ergebnisse abzielenden Politik ${ }^{190}$. Insofern schloß der Botschafter, »wenn die Wahl der französischen Regierung auf François-Poncet fällt, so muß seine Ernennung uns willkommen sein, und ich könnte mir wohl denken, daß die Sache nicht schlecht ausgeht « ${ }^{191}$.

$\mathrm{DaB}$ die Entsendung François-Poncets nach Berlin der französischen Deutschlandpolitik neuen Schwung geben würde, war abzusehen. Der designierte Botschafter arbeitete bis zu seiner Ernennung ein Arbeitsprogramm aus, das er in einer 48 -seitigen Note zusammenfaßte ${ }^{192}$. André François-Poncet

${ }^{189}$ Zur Charakterisienung des deutschen Botschafters in Paris siehe GRAML, Zwischen Stresemann und Hitler, S. 31.

${ }^{190}$ Diese Einschätzung bestätigt PAPEN, Wahrheit, S. 110f.: »Gerade im September [1931] waren Anzeichen vorhanden, daB die französische Regierung zum Einlenken bereit sei. Nach den Niederlagen, die ihre Diplomatie dem Reich in den letzten Wochen beigebracht hatte, wäre dies durchaus plausibel gewesen. Das erste Anzeichen dafür war in der Entsendung François-Poncets zu sehen [...]. Die Emennung François-Poncets zum französischen Botschafter in Berlin konnte als Wink Lavals verstanden werden, nunmehr sei die Zeit des Ausgleichs und der Verständigung gekommen «.

${ }^{191}$ Schreiben des Botschafters in Paris vom 16. Juli 1931 an den Ministerialdirektor Köpke, in: ADAP, B, Bd. 18, Nr. 54, S. 94-96.

${ }^{192} \mathrm{Vgl}$. Note sur une Commission économique franco-allemande vom 13. August 1931, in: AMAE, RC-Allemagne, Vol. 69, S. 12-57. Die ungezeichnete Note ist nicht nur aus inhaltlichen Gründen François-Poncet zuzuschreiben. Er wird an anderer Stelle als deren Autor auch genannt, vgl. Note vom 22. September 1931, in: AMAE, RC-Allemagne, Vol. 69, S. 72f., hier S. 72. Siehe auch den Hinweis Ministerpräsident Lavals gegenüber dem deutschen Botschafter von Hoesch auf eine von François-Poncet verfaßte Aufzeichnung, 
schlug in dem Papier die Einrichtung einer deutsch-französischen Wirtschaftskommission ${ }^{193}$ vor, die die Handelsbeziehungen zwischen beiden Ländern überprüfen ${ }^{194}$, die bestehenden Kartelle verbessern und neue Absprachen initiieren sollte ${ }^{195}$. Außerdem sollte sie die verschiedenen Möglichkeiten der Kapitalverflechtung in deutsch-französischen Dachgesellschaften zum Beispiel $^{196}$ bzw. den Abschluß binationaler Projektgesellschaften für bestimmte Aufbau- und Entwicklungsvorhaben in Rußland, Mittel- und Osteuropa sowie in den französischen Kolonien prüfen ${ }^{197}$. Mit diesem Wirtschaftsprogramm ${ }^{198}$ verfolgte der designierte Botschafter einen politischen Zweck: »La collaboration économique peut, dans une certaine mesure, détendre l'atmosphère politique; elle ne saurait accomplir les grandes choses si la collaboration politique

ADAP, B, Bd. XVIII, Nr. 134, S. 266-269, hier S. 268 und den Hinweis André FrançoisPoncets gegenüber Harry Graf Kessler, in: DERS., Tagebücher, S. 715. Siehe auch HEYDE, Reparationen, S. 266f.

${ }^{193}$ André François-Poncet kann auf die Idee kein Urheberrecht beanspruchen. Nach dem Bekanntwerden der deutsch-österreichischen Zollunionspläne im Frühjahr 1931 hatten in Paris Überlegungen zu einer wirtschaftlichen und finanziellen Zusammenarbeit zwischen Deutschland und Frankreich wieder Konjunktur. Eine Reihe französischer Parlamentarier gründeten zu diesem Zweck Ende Juli 1931 ein »Comité d'Entente internationale«, das ein deutsches Gegenstück bekommen sollte. Siehe den Bericht des Botschafters von Hoesch an das Auswärtige Amt vom 30. Juli 1930, in: ADAP, B, Bd. XVIII, Nr. 95, S. 184-187. Der französischen Regierung war diese Privatinitiative »unheimlich«, vgl. Telegramm Nr. 852 des deutschen Botschafters von Paris von Hoesch an das Auswärtige Amt vom 13. August 1931, in: ADAP, B, Bd. XVIII, Nr. 134, S. 266-269, hier S. 268. Insofern war François-Poncets Vorschlag auch ein Versuch der französischen Regierung, die Initiative auf dem deutsch-französischen Gebiet zurückzugewinnen.

${ }^{194}$ Note sur une Commission économique franco-allemande vom 13. August 1931, in: AMAE, RC-Allemagne, Vol. 69, S. 12-57, hier S. 20ff. Die negative Außenhandelsbilanz Frankreichs gegenüber Deutschland schrieb André François-Poncet zum Teil dem deutsch-französischen Handelsvertrag von $1927 \mathrm{zu}$. Er forderte infolgedessen eine Korrektur und Anpassung des Vertrages, d. h. bestimmter Zolltarife, durch die deutschfranzösische Wirtschaftskommission. Eine Zollunion mit Deutschland lehnte der designierte Botschafter - im Gegensatz zu den privaten Initiativen - ab, ibid. S. 22.

195 Ibid. S. 29ff. André François-Poncet schlug eine »europäische Regelung« für Holz und Kohle, für elektrische Energie und die chemische Industrie, für die Textilindustrie und das Transportwesen (Bahnen, Schiffe, Flugzeuge) vor. Im übrigen verwies er auf den im Mai 1931 in Genf vorgestellten - und von ihm erarbeiteten - plan constructif.

196 Tbid. S. 36ff.

197 Ibid. S. 44ff.

198 André François-Poncet hatte die Grundzüge des Programms dem deutschen Botschafter in Paris, von Hoesch, schon Ende Juli 1931 erläutert, siehe Telegramm Nr. 813 vom 31. Juli 1931 des deutschen Botschafters in Paris von Hoesch an das Auswärtige Amt, in: ADAP, B, Bd. XVIII, Nr. 98, S. 191-193, hier S. 193. Ausführlicher und dem skizzierten Programm entsprechend gegenüber dem österreichischen Geschäftsmann Richard Freund, in: ADAP, B, Bd. XVUI, Nr. 180, S. 392-396, hier S. 393f. 
marche de pair avec elle ${ }^{199}$. Der politischen Zusammenarbeit stünden jedoch das Deutschland von Hitler, Hugenberg und des Stahlhelms entgegen:

Toute la question est de savoir si le Chancelier [sic!] Brüning parviendra à remonter la pente du nationalisme exaspéré et anti-français dans son pays, et s'il pourra lui-même assez se dégager des éléments de son propre gouvernement qui nous sont hostiles, pour ouvrir vraiment les portes à une ère nouvelle ${ }^{200}$.

André François-Poncet glaubte, daß die Einrichtung einer deutsch-französischen Wirtschaftskommission die Position Brünings stärken könnte. So könnten ihr Sturz der verhindert und die Bildung einer antifranzösischen Regierung vermieden werden. Außerdem würde die deutsch-französische Wirtschaftskommission »le règlement des comptes« erleichtern. Grïnde genug, die Wirtschaftskommission bei nächster Gelegenheit, und das hieß beim bevorstehenden Besuch des französischen Ministerpräsidenten und Außenministers in Berlin, einzurichten. Zöge sich Frankreich im Gegenteil aus Deutschland zurück, gewährte das Land und seine Banken dem Reich keine Kredite mehr und forderten die gegebenen aus Deutschland zurück, müßte Frankreich nicht nur mit finanziellen Verlusten rechnen. »Elle [l'opération] nous conduirait, en outre, à abandonner l'Allemagne à son sort, à la livrer au chaos nationaliste ou bolcheviste, à la laisser peut-être, ainsi, ébranler l'Europe entière «"

Motive, Methoden und Mittel des wirtschaftlichen Verständigungsprogramms François-Poncets erinnern an seinen im Frühjahr 1931 in Genf vorgestellten "plan constructif «, der ja - wie gesehen -nur eine Aktualisierung und in gewissen Punkten eine Erweiterung seines Anfang der 20er Jahre in Genua präsentierten programme positif war. Insofern faßte das Programm für die deutsch-französische Wirtschaftskommission seine im Laufe der 20er Jahre modifizierten deutschlandpolitischen Vorstellungen zusammen. Hatte André François-Poncet bis Mitte der 20er Jahre die konfrontativen Elemente betont, so schwenkte er nicht zuletzt unter dem Einfluß des französischen Schwerindustriellenverbandes und insbesondere seines Generalsekretärs Robert Pinots auf die seit dem Vertrag von Locarno in Frankreich vorherrschende Verständigungslinie ein. Die kooperativen Elemente in seinen deutschlandpolitischen Vorstellungen zu betonen, bereitete André FrançoisPoncet keine Probleme. Schließlich hatte er - aus dem Studium des Deutschen und der Deutschen - vor dem Ersten Weltkrieg ein dichotomes Deutschlandbild entwickelt, das in weiten Teilen dem klassischen Klischee der Franzosen entsprach. Auf dieser Grundlage konnte er je nach der aktuellen Deutschlandwahrnehmung problemlos seine deutschlandpolitischen Vorstellungen modifi-

${ }^{199}$ Note sur une Commission économique franco-allemande vom 13. August 1931, in: AMAE, RC-Allemagne, Vol. 69, S. 12-57, hier S. 54.

${ }^{200}$ Ibid.

201 Ibid. S. 18. 
zieren $^{202}$. Insofern stellt das Eintreten François-Poncets für eine deutschfranzösische Annäherung über eine wirtschaftliche Zusammenarbeit nach 1925 keinen Bruch mit seinen Vorkriegsvorstellungen dar, sondern einen Übergang, der auch wieder in umgekehrter Richtung möglich sein würde. Kooperation und Konfrontation waren zwei Seiten einer Medaille, die je nach Bedarf gezeigt werden konnten. André François-Poncet suchte - und das machte seinen Ansatz aus - auf dem (Um)Weg über die Wirtschaft, und auch der Kultur eine Annäherung zwischen Frankreich und Deutschland zu erreichen, die zu einer politischen Verständigung führen sollte. Dieses wirtschaftliche Annäherungs- und Verständigungskonzept versuchte er Anfang der 30er Jahre umzusetzen. Ohne Erfolg. Machte ihm - wie gesehen - im Frühjahr 1931 der deutsch-österreichische Zollunionsplan einen Strich durch die Rechnung, ging die Reichsregierung im Sommer 1931 trotz der schwierigen Lage Deutschlands auf den ersten Blick aus innenpolitischen, im Grunde aber aus reparationspolitischen Gründen nicht auf das wirtschaftspolitische Kalkül ein. André François-Poncet führte das auf den Einfluß der nationalistischen Opposition in Deutschland zurïck. Infolgedessen versuchte er - wie gezeigt werden konnte - mit weitreichenden Angeboten zur Revision des Versailler Vertrages einer deutsch-französischen Annäherung den Weg zu ebnen. Diese politische Abkürzung der wirtschaftlichen Annäherung war aber weder in Frankreich durchsetzbar, noch von der Reichsregierung gewollt. Die wollte unter Brünings Leitung den Reparationszahlungen ein Ende setzen und selbiges nicht durch eine wirtschaftliche Zusammenarbeit mit Frankreich hinauszögern. Dies erkannte André François-Poncet nicht. Er zog sich, eigentlich folgerichtig, auf sein Wirtschaftsprogramm zurück, das eine deutsch-französische Kommission - so weit wie möglich - auf den Weg bringen sollte. Gleichzeitig drängte er auf den Botschafterposten in Berlin, um seinem wirtschaftlichen Annäherungs- und Verständigungsprogramm bei der Reichsregierung zum Durchbruch zu verhelfen. Ob ihm das gelang, ist in den folgenden Kapiteln zu untersuchen.

${ }^{202} \mathrm{DaB}$ historische Fremdbilder nach wie vor je nach Bedarf aktualisiert werden, zeigt Dieter TIEMANN, Das Bild im Kopf - Stereotypen früher und heute, in: Vis-à-vis: Deutschland und Frankreich. Begleitbuch zur Ausstellung im Haus der Geschichte der Bundesrepublik Deutschland, Bonn, 4. Juni 1998 bis 20. September 1998, Köln 1998, S. 27-38. 
